\title{
GENERATIONAL RISK - IS IT A BIG DEAL?: SIMULATING AN 80-PERIOD OLG MODEL WITH AGGREGATE SHOCKS
}

\author{
Jasmina Hasanhodzic \\ Laurence J. Kotlikoff \\ Working Paper 19179 \\ http://www.nber.org/papers/w19179 \\ NATIONAL BUREAU OF ECONOMIC RESEARCH \\ 1050 Massachusetts Avenue \\ Cambridge, MA 02138 \\ June 2013
}

We thank Ken Judd, Thomas Sargent, Kent Smetters, Kerk Phillips, Rick Evans, Karl Schmedders, Simon Gilchrist, and Alisdair McKay for helpful comments. The views expressed herein are those of the authors and do not necessarily reflect the views of the National Bureau of Economic Research.

NBER working papers are circulated for discussion and comment purposes. They have not been peerreviewed or been subject to the review by the NBER Board of Directors that accompanies official NBER publications.

(C) 2013 by Jasmina Hasanhodzic and Laurence J. Kotlikoff. All rights reserved. Short sections of text, not to exceed two paragraphs, may be quoted without explicit permission provided that full credit, including (C) notice, is given to the source. 
Generational Risk - Is It a Big Deal?: Simulating an 80-Period OLG Model with Aggregate Shocks

Jasmina Hasanhodzic and Laurence J. Kotlikoff

NBER Working Paper No. 19179

June 2013

JEL No. E0

\begin{abstract}
The theoretical literature on generational risk assumes that this risk is large and that the government can effectively share it. To assess these assumptions, this paper calibrates and simulates 80 -period, 40-period, and 20-period overlapping generations (OLG) life-cycle models with aggregate productivity shocks.

Previous solution methods could not handle large-scale OLG models such as ours due to the well-known curse of dimensionality. The prior state of the art uses sparse-grid methods to handle 10 to 30 periods depending on the model's realism. Other methods used to solve large-scale, multi-period life-cycle models rely on either local approximations or summary statistics of state variables. We employ and extend a recent algorithm by Judd, Maliar, and Maliar (2009, 2011), which restricts the state space to the model's ergodic set. This limits the required computation and effectively banishes the dimensionality curse in models like ours.
\end{abstract}

We find that intrinsic generational risk is quite small, that government policies can produce generational risk, and that bond markets can help share generational risk. We also show that a bond market can mitigate risk-inducing government policy. Our simulations produce very small equity premia for three reasons. First, there is relatively little intrinsic generational risk. Second, aggregate shocks hit both the young and the old in similar ways. And third, artificially inducing risk between the young and the old via government policy elicits more net supply as well as more net demand for bonds, by the young and the old respectively, leaving the risk premium essentially unchanged. Our results hold even in the presence of rare disasters, very high risk aversion, persistent productivity shocks, and stochastic depreciation. They echo other findings in the literature suggesting that macroeconomic fluctuations are too small to have major microeconomic consequences.

Jasmina Hasanhodzic

Department of Economics

Boston University

270 Bay State Road

Boston, MA 02215

jah@bu.edu

Laurence J. Kotlikoff

Department of Economics

Boston University

270 Bay State Road

Boston, MA 02215

and NBER

kotlikoff@gmail.com 


\section{Introduction}

Economists have examined generational risk and its mitigation via government policy in a number of theoretical models (e.g. Bohn (1998), Shiller (1999), Rangel and Zeckhauser (2001), Smetters (2003), Krueger and Kubler (2006), and Ball and Mankiw (2007)). This literature presumes that generational risks are large and that the government is capable of sharing them.

This paper questions both propositions. It does so by calibrating and simulating 80period, 40-period, and 20-period overlapping generations (OLG) life-cycle models with aggregate productivity shocks. Solving such large-scale models without recourse to local approximations or potentially inapplicable aggregations of state variables has heretofore been impossible due to the well-known curse of dimensionality. But a new computational method, developed by Ken Judd, Lilia Maliar, and Serguei Maliar (2009, 2011), lifts this curse, taking us beyond the roughly 10- to 30-period limit reached by Krueger and Kubler (2004, 2006) using their sparse grid projection method. We employ this method, and extend it to allow for the bond market.

In our models agents work full time prior to retirement. They do so in the context of uncertainty about the economy's future productivity and, thus, uncertainty about the compensation accruing to their supplies of labor and capital. Government enters our model through a take-as-you-go policy in which workers are forced to hand over resources each period to the elderly. We consider three such policies. In the first, the government takes a fixed amount from workers each period independent of the economy's state. In the second, the government's taking is proportional to workers' earnings. The third is variable (progressive), with the amount taken far higher when wages are higher. We calibrate the no-policy model using standard parameter values found in the real business cycle literature, including those governing aggregate productivity shocks.

Our policies illustrate that intergenerational redistribution dominates business cycle fluctuations in determining the economy's long-run position. The variable policy is intentionally unrealistic to illustrate that government actions can, in principle, destabilize the economy and foster, not mitigate, generational risk. It can also dramatically alter asset market demands by age.

There are three aspects of generational risk to consider. First, one can place all generations into Rawl's (1971) original position (before anyone is born) and ask whether, abstracting from trend growth, being born at date $\mathrm{X}$ is materially worse, measured in terms of expected lifetime utility, than being born at date Y. Second, one can study the degree of risk that any given generation faces over its lifetime. All generations could have the same 
expected lifetime utilities but still be very unsure what utility they will realize. Third, one can examine the scope for concomitant generations to share their risk over their remaining lifetimes.

Generational risk presupposes aggregate risk, i.e., risk that cannot be eliminated via risk sharing across or within generations. But, as Lucas (1987) and Krusell and Smith (1999) suggest, albeit in models with infinitely-lived agents, such purely aggregate or macro economic risk may be small. The presumed driver of macroeconomic fluctuations is shocks to productivity. But standard calibration of productivity shocks implies a coefficient of variation of the level of total factor productivity of only 0.0313. And in our model, this limited productivity variation implies rather small coefficients of variations of the wage and the return to capital -0.0361 and 0.0326 , respectively. Yet it is these factor price shocks that different generations experience as macroeconomic risk. Adding rare disasters to the productivity shock process as in Rietz (1988), Barro (2006), and Weitzman (2007) raises these risk metrics, but not by much. The new coefficients of variation of productivity, the wage, and the return to capital are 0.058, 0.071, and 0.065, respectively. Alternatively, incorporating stochastic depreciation, as in Ambler and Paquet (1994) and Furlanetto and Seneca (2011), also makes little difference. The three coefficients are now 0.029, 0.043, and 0.060 .

These fundamentals and the ability of cohorts to self insure by saving on their own help explain our main finding of very limited generational risk. Moreover, the fact that wage rates and returns to capital are being hit by the same shock, exhibiting a correlation coefficient in our baseline model of 0.515 , means that substantial risk sharing occurs automatically since risk sharing entails having agents experiencing, directly or indirectly, the same shocks. Even in the model with stochastic depreciation automatic risk sharing arises via the following general equilibrium effects. First, an $X$ percent depreciation-induced reduction in the stock of capital in period $t$ is mitigated, from the perspective of capital owners, by increases in the marginal productivity of capital in period $t+1$ and thereafter. Second, the reduction in capital stock hurts workers via a reduction in the marginal productivity of labor, i.e., in wages in period $t+1$ and thereafter.

Our principal findings number six. First, absent government policy, differences in expected lifetime utilities across generations, measured on a consumption-equivalent basis, are less than 0.05 percent. Hence, Rawlsian justice prevails from an ex-ante, original position and there is little risk associated with when one is born. This is to be expected given the model's stationarity and our choice of initial conditions.

Second, there is limited scope for sharing generational risks among contemporaneous generations on an ex-post basis, i.e., after the generations have been born. As shown by 
Abel and Kotlikoff (1988), full risk sharing among contemporaneous agents with homothetic preferences requires equal percentage changes in consumption from one period to the next. Hence, one can measure the potential for generational risk sharing by calculating the percentage adjustment in consumption of each agent at each point in time needed to produce a uniform percentage change across all agents alive at that point in time. In our base model, the largest such absolute adjustment of any agent observed over more than 600 years is less that 1 percent. Moreover, establishing full intergenerational risk sharing among all those alive between a given period and the next entails a trivially small gain in expected utility except when take-as-you-go policy is intentionally overly variable (progressive).

Third, letting agents share risk via a risk-free bond market does little to modify these results. Moreover, since there is little risk to share, there is little demand for these bonds relative to supply, which explains their low price. Low prices for safe bonds means, of course, high safe rates of return and a small equity premium. Indeed, in our model, the equity premium is trivially small, making the equity premium puzzle even greater. The demanders of safe bonds are, as one would expect, the very young, who face the greatest risk to their consumption from the productivity shock. The suppliers are the very old, who face the least consumption risk, since their consumption depends not just on the risky return to their assets, but also on the safe principal of their assets.

Applying variable taking policy flips the age pattern of net bond demands. This policy transforms good (bad) times - when productivity is high (low) - into bad (good) times for the young. Consequently, the best way for the young to hedge their risk is to hold something that does well in good times, namely stocks. This finding that the young hold bonds is opposite to that in Bodie, Merton, and Samuelson (1992) and other models in which the main asset of the young - their wages - is not strongly correlated with the return to stocks. In those models, having wages is like already holding bonds. In our model, having wages is like already holding stocks.

Fourth, generational risk arises in our model not from a failure of agents to pool risk that strongly needs to be pooled, but from government policy itself. All three take-as-you-go, intergenerational redistribution policies undermine Rawlsian justice, producing significantly different levels of lifetime expected utility of those born before and after the policies are introduced. In addition, once cohorts are born, government policy actually exacerbates generational risk, albeit not by much.

Fifth, government policy can dramatically alter the structure of bond demand turning the young into net sellers rather than net buyers of bonds and doing the opposite for the old.

Sixth, the findings suggest that secular policy changes is where the real action is when it 
comes to macroeconomics.

The paper next reviews the literature on generational risk sharing. Sections 3 and 4 describe the model and its calibration. Section 5 presents the solution algorithm. Section 6 presents results, and Section 7 conducts sensitivity analysis of those results. Section 8 concludes.

\section{Literature Review}

The theoretical proposition that generational risk can and should be shared via fiscal policy is well established. But the above-cited studies beg the question of how much generational risk exists and how well government policies can share it. The main impediment for answering this question has been the difficulty of simulating realistic life-cycle models with long-lived agents in economies subject to aggregate shocks. Such models feature too many state variables. In our model, for example, there are 80 state variables reflecting the shock itself and the distribution of wealth across the 80 age groups.

The reason the asset holdings of other agents matter for any given agent's behavior is that agents differ in their preferences. A 70-year-old who will die at 100 is not interested in consuming in any year after he is dead. But a contemporaneous 30-year-old is interested in consuming during some of those years. These preference differences mean that who holds what will affect the economy's overall saving and thus the course of future factor prices. And it is the course of future factor prices that drives each agent's life-cycle choices.

Unfortunately, finding an exact solution to our 80-period model entails solving for a fixed point in age-specific choice functions, each of which has 80 arguments, and doing so for all possible configurations of the state space. This is beyond the capacity of any current computer and, arguably, any future computer.

Judd, Maliar, and Maliar (2009, 2011), building on Marcet (1988), overcome this dimensionality curse by seeking internally consistent solutions for the choice functions over the space of state variables that the economy will actually occupy. Their method foregoes solving for the model's behavior in states that will never or essentially never materialize given the ergodicity of the stochastic process driving the economy as well as its initial conditions. The authors dub their solution the Generalized Stochastic Simulation Algorithm or GSSA. GSSA is, perforce, an approximation method, but it offers a significant advance over other approximate approaches in overcoming the dimensionality curse. In particular, it does not use summary statistics of state variables or require global behavior to emulate local behavior.

Ríos-Rull $(1994,1996)$ uses local perturbation methods to solve large-scale (55-period) 
OLG models subject to aggregate productivity shocks. These papers consider, in part, whether the degree of completeness in risk-sharing arrangements materially affects the economy and conclude it does not. The studies also find extremely small equity premia. RíosRull's findings generally accord with those presented here although we a) consider a continuum of shocks rather than a discrete set and b) do not extrapolate from the economy's non-stochastic transition path.

Krusell and Smith $(1997,1998)$ take a different approach. They point out that agents care only about the evolution of factor prices and, by extension, tax policy. They then approximate the true functions, which relate the evolution of factor prices to the entire vector of state variables, with functions whose arguments are summary statistics of the state variables, particularly the mean of the wealth distribution.

Their method does well within their context, namely a population of infinitely lived agents who differ with respect to their wealth and labor income. But, as the authors point out, their method's success is connected to the similarity of consumption behavior of agents, specifically their uniform propensities to consume.

Gourinchas (2000) and Storesletten, Telmer, and Yaron (2007) apply the Krusell and Smith approach in OLG models. They find it works well, but Krueger and Kubler (2004) argue that Krusell and Smith's low-dimensional approximation approach cannot adequately handle more realistic OLG economies. ${ }^{1}$ As an alternative, Krueger and Kubler approximate the equilibrium policy functions over the full state space. To overcome the curse of dimensionality, they implement Smolyak's (1963) algorithm, which guarantees uniform approximation over a small (sparse) set of points in the multidimensional hypercube. ${ }^{2}$

Krueger and Kubler (2006) use their method to study unfunded social security in a life-cycle model similar to ours, albeit with nine periods of life and four discrete productivity shocks. They also incorporate stochastic depreciation, which is tailored to produce significant risk-sharing opportunities between workers and retirees - indeed, large enough to permit a Pareto improvement à la Merton (1983). However, the large negative correlation between wages and asset returns resulting from their depreciation process is outside Davis and Willen's (2000) empirical estimates.

As an alternative to positing highly variable stochastic depreciation, we use government policy to produce risk sharing opportunities between age groups. Specifically, we consider a government taking policy that turns good (bad) times into bad (good) times for the young, and good (bad) times into better (worse) times for the old. We then show that a bond

\footnotetext{
${ }^{1}$ Our analysis also points to the inadequacy of the Krusell-Smith algorithm in our setting, in line with Krueger and Kubler (2004).

${ }^{2}$ See also Malin, Krueger, and Kubler (2011) for general description of this method.
} 
market can help pool the resulting generational risk.

\section{The Model}

Our model features $G$ overlapping generations with shocks to total factor productivity. Each agent works full time through retirement age $R$, dies at age $G$, and maximizes expected lifetime utility. There are no borrowing or short asset sale constraints and no adjustment costs, so firms maximize static profits. Finally, the government has a take-as-you-go policy that takes either a fixed or state-dependent amount from workers each period and distributes the proceeds uniformly among retirees.

\subsection{Endowments and Preferences}

The economy is populated by $G$ overlapping generations that live from age 1 to age $G$. All agents within a generation are identical and are referenced by their age $g$ and time $t$. Each cohort of workers supplies 1 unit of labor each period. Hence, total labor supply equals the retirement age $R$. Utility is time-separable and isoelastic, with risk aversion coefficient $\gamma$ :

$$
u(c)=\frac{c^{1-\gamma}-1}{1-\gamma}
$$

\subsection{Technology}

Production is Cobb-Douglas with output $Y_{t}$ given by

$$
Y_{t}=z_{t} K_{t}^{\alpha} L_{t}^{1-\alpha}
$$

where $z$ is total factor productivity, $\alpha$ is capital's share of output, and $L_{t}$ is labor demand, which equals $R$, labor supply. Equilibrium factor prices are given by

$$
\begin{aligned}
& w_{t}=z(1-\alpha)\left(\frac{\sum_{g=1}^{G} \theta_{g, t-1}}{R}\right)^{\alpha}, \\
& r_{t}=z \alpha\left(\frac{\sum_{g=1}^{G} \theta_{g, t-1}}{R}\right)^{\alpha-1} .
\end{aligned}
$$


Total factor productivity, $z$, obeys

$$
\ln \left(z_{t+1}\right)=\rho \ln \left(z_{t}\right)+\epsilon_{t+1}+v_{t+1}
$$

where $\epsilon_{t+1} \sim \mathcal{N}\left(0, \sigma^{2}\right)$ and $v_{t+1}$ is a rare disaster shock satisfying

$$
v_{t+1}= \begin{cases}\ln (1-d), & \text { with probability } \mathrm{p} \\ 0, & \text { otherwise }\end{cases}
$$

This specification for $v_{t+1}$ follows Barro (2006), although his model features a representative agent and Lucas tree production, with no aggregate saving and investment.

\subsection{Financial Markets}

Households save and invest in either risky capital or one-period safe bonds. Investing 1 unit of consumption in bonds at time $t$ yields $1+\bar{r}_{t}$ units in period $t+1$. The safe rate of return, $\bar{r}_{t}$, is indexed by $t$ since it is known at time $t$ although it is received at time $t+1$. The total demand for assets of household age $g$ at time $t$ is denoted by $\theta_{g, t}$, and its share of assets

invested in bonds is denoted by $\alpha_{g, t}$. Households enter period t with $\theta_{g-1, t-1}$ in assets, which corresponds to the total assets they demanded the prior period. Since investment decisions are made at the end of the period, the aggregate supply of capital in period $t, K_{t}$, is the sum of assets brought by the households into period $t$, i.e.

$$
K_{t}=\sum_{g=1}^{G} \theta_{g, t-1}
$$

Markets are incomplete; households cannot insure against productivity shocks or against the date and state in which they will be born. Hence, the model potentially permits considerable scope for generational risk sharing.

\subsection{Government}

We consider three alternative take-as-you-go policies, which we call variable, fixed, and proportional. Under the variable policy, the percentage of the wage taken by the government from each worker is linear in the wage. Under the fixed policy, taking is fixed and independent 
of the wage. Under the proportional policy, the government takes a fixed percentage of the wage from each worker. Total takings are distributed uniformly among retirees. Let $H_{g, t}$ denote the government taking from the age $g$ household at time $t$, and $B_{g, t}$ government giving to the age- $g$ household at time $t$. Then

$$
H_{g, t}= \begin{cases}\bar{H}, & \text { with fixed policy } \\ \mu\left(w_{t}\right) w_{t} \ell_{g}, & \text { with variable policy } \\ \tau w_{t} \ell_{g}, & \text { with proportional policy } \\ 0, & \text { otherwise }\end{cases}
$$

where

$$
\mu\left(w_{t}\right)=a \underline{w}+\frac{b \bar{w}-a \underline{w}}{\bar{w}-\underline{w}}\left(w_{t}-\underline{w}\right)
$$

where $\underline{w}$ and $\bar{w}$ are the estimates of the minimum and maximum values of $w$. Parameters $a$, $b, \tau, \underline{w}$, and $\bar{w}$ are described in Section 4. Finally,

$$
B_{g, t}= \begin{cases}\left(1-\ell_{g}\right) \frac{\sum_{g=1}^{G} H_{g, t}}{L}, & \text { with government } \\ 0, & \text { otherwise. }\end{cases}
$$

Implicit in the above formulation is each period's takings equal that period's givings:

$$
\sum_{g=1}^{G} H_{g, t}=\sum_{g=1}^{G} B_{g, t}
$$

As shown in Green and Kotlikoff (2008), this policy can be labeled to produce whatever time path of explicit and implicit debts the government wishes to report.

\subsection{Household Problem}

Households of age $g$ in state $(s, z)$ maximize expected remaining lifetime utility given by

$$
V_{g}(s, z)=\max _{c, \theta, \alpha}\left\{u(c)+\beta \mathrm{E}\left[V_{g+1}\left(s^{\prime}, z^{\prime}\right)\right]\right\}
$$


subject to

$$
\begin{aligned}
& c_{1, t}=\ell_{1} w_{t}-\theta_{1, t}-H_{1, t}+B_{1, t}, \\
& c_{g, t}=\ell_{g} w_{t}+\left[\alpha_{g-1, t-1}\left(1+\bar{r}_{t-1}\right)+\left(1-\alpha_{g-1, t-1}\right)\left(1+r_{t}\right)\right] \theta_{g-1, t-1}-\theta_{g, t}-H_{g, t}+B_{g, t}, \\
& \quad \text { for } 1<g<G, \text { and } \\
& c_{G, t}=\ell_{G} w_{t}+\left[\alpha_{G-1, t-1}\left(1+\bar{r}_{t-1}\right)+\left(1-\alpha_{G-1, t-1}\right)\left(1+r_{t}\right)\right] \theta_{G-1, t-1}-H_{G, t}+B_{G, t},
\end{aligned}
$$

where $c_{g, t}$ is the consumption of a $g$-year old at time $t$ and (13)-(15) are budget constraints for age group 1, those between 1 and $G$, and that for age group $G$.

\subsection{Equilibrium}

At time $t$, the economy's state is $\left(s_{t}, z_{t}\right)$, with $s_{t}=\left(\theta_{1, t-1}, \ldots, \theta_{G-1, t-1}\right)$ denoting the set of age-specific asset holdings. Given the initial state of the economy $s_{0}=\left(\theta_{1,-1}, \ldots, \theta_{G-1,-1}, z_{0}\right)$, the recursive competitive equilibrium is defined as follows:

Definition. The recursive competitive equilibrium is governed by the collection of the value functions and the household policy functions for total savings $\theta_{g}(s, z)$, the share of savings invested in bonds $\alpha_{g}(s, z)$, and consumption $c_{g}(s, z)$ for each age group $g$, the choices for the representative firm $K(s, z)$ and $L(s, z)$, the government policy $H(s, z)$ and $B(s, z)$, as well as the pricing functions $r(s, z), w(s, z)$, and $\bar{r}(s, z)$ such that:

1. Given the pricing functions, the value functions (12) solve the recursive problem of the households subject to the budget constraints (13)-(15), and $\theta_{g}, \alpha_{g}$, and $c_{g}$ are the associated policy functions for all $g$ and for all dates and states.

2. Wages and rates of return on capital satisfy (3) and (4), i.e. the firm maximizes profits at each point in time for given $w$ and $r$.

3. The government budget constraint (11) is satisfied.

4. All markets clear: Labor and capital market clearing conditions are implied by $L_{t}=R$ and (7). Since bonds are in zero net supply, bond market clearing requires

$$
\sum_{g=1}^{G} \alpha_{g}(s) \theta_{g}(s)=0 .
$$


Market clearing conditions in labor, capital, and bond markets and satisfaction of household budgets imply market clearing in consumption.

Finally, for all age groups $g=1, \ldots, G-1$, optimal intertemporal consumption and investment choice satisfies

$$
\begin{aligned}
& 1=\beta \mathrm{E}_{z}\left[\left(1+r\left(s^{\prime}, z^{\prime}\right)\right) \frac{u^{\prime}\left(c_{g+1}\left(s^{\prime}, z^{\prime}\right)\right)}{u^{\prime}\left(c_{g}(s, z)\right)}\right] \text { and } \\
& 0=\mathrm{E}_{z}\left[u^{\prime}\left(c_{g+1}\left(s^{\prime}, z^{\prime}\right)\right)\left(\bar{r}(s, z)-r\left(s^{\prime}, z^{\prime}\right)\right)\right]
\end{aligned}
$$

where $\mathrm{E}_{z}$ is the conditional expectation of $z^{\prime}$ given $z$. Note that the endogenous part of the state next period, $s^{\prime}$, is determined by the asset demands chosen the period before. Hence, the only stochastic element of the next period's state vector is the aggregate productivity level, $z^{\prime}$.

\section{Calibration}

We first investigate generational risk and its potential for mitigation in the 80-period, nobond economy. We then turn to 40- and 20-period models with bonds to examine how a bond market affects generational risk and to assess the size of equity premia. Including a bond market entails approximating $G$ additional functions $(G-1$ bond shares plus the annual safe rate of return, all of which are functions of the state variables). This makes converging to a fixed point in the function space harder to achieve.

The rest of the parameters are calibrated as follows.

\subsection{Endowments and Preferences}

We consider values for $\gamma \in\{2,5,15\}$. In our 80-period model agents work for 45 periods and live for 80. In the 40-period model, each period represents 1.5 years (ages 20 through 80), with retirement after 30 periods. In the 20-period model, each period represents 3 years (ages 20 through 80 ), with retirement after 15 periods. We set the quarterly subjective discount factor, $\beta$, at 0.99 , as is standard in the macroeconomics literature. This implies values of $\beta$ of $0.96,0.94$, and 0.89 in the 80-, 40-, and 20-period models, respectively. 


\subsection{Technology}

Quarterly values for $\rho$ and $\sigma$ are 0.95 and 0.01 , respectively. This corresponds to values of 0.8145, 0.7351, 0.5404 for $\rho$, and 0.0186, 0.0217, 0.0269 for $\sigma$, in the 80-, 40-, and 20-period models, respectively. The probability of rare disaster, $p$, is 3 percent per year in the 80 -period model and 1.7 percent per year in the 40- and 20-period models. The fraction $d$ by which productivity contracts when a disaster hits is 0.2 in the 80- and 40-period models and 0.15 in the 20-period model. Capital share of output, $\alpha$, equals 0.33 .

\subsection{Government}

The variable policy parameters $a$ and $b$ equal 0.1 and 0.4 , respectively. The values for $\underline{w}$ and $\bar{w}$ are estimated as the minimum and maximum wage from a previous run of the same model (to start, we use the minimum and maximum wage from the no-policy model). This yields $\underline{w}$ and $\bar{w}$ of 1.572 and 1.976 in the 80-period model, and 0.674 and 0.872 in the 20-period model. ${ }^{3}$ The resulting taking rates range from 5 percent to 40 percent of the wage in the 80 -period model, and from 9 percent to 40 percent of the wage in the 20-period model. Note that (8) and (9), together with the above choice of parameters, imply that the variable policy is countercyclical, i.e., the correlation between net wage and $z$ is negative. The reason for this negative correlation is that as the wage rises, the taking rate is applied to all wages, not just the increment of wages.

The fixed policy taking, $\bar{H}$, is set as the sample mean of the variable taking $\mu\left(w_{t}\right) w_{t}$ from the corresponding variable policy model simulation. This equals 0.333 , or 20 percent of the average wage, in the 80-period model. Similarly, the proportional taking rate $\tau$ equals 20 percent of the wage, which is the average taking rate from the variable policy model.

\section{Algorithm}

Our algorithm consists of an inner loop and an outer loop. In the outer loop we solve for the asset demand functions of each age group by applying Judd, Maliar, and Maliar's (2009, 2011) generalized stochastic simulation algorithm (GSSA) to our OLG setting. We start by making an initial guess of generation-specific asset demand functions $\theta_{g}$ (which amounts to guesses of the consumption functions) as polynomials in the state variables. Next we take a draw of the path of $z$ 's for $T$ periods and run the model forward over those periods using the guessed asset demand functions to compute the state variables in each period. Next, for

\footnotetext{
${ }^{3}$ Government policies are not considered in the 40-period model.
} 
each age group, $g$, we evaluate the Euler condition to determine what age group $g$ 's asset demand (or, equivalently, consumption) should be in each period $t$. This evaluation is based on the derived period $t$ state variables and the current guessed asset demand (equivalently, consumption) function of the agent age $g+1$. We then regress these time series of generationspecific asset demands on the state variables and use the regression estimates to update the corresponding polynomial coefficients. We iterate the updating of these functions based, always, on the same draw of the path of $z$ 's until asset demand functions converge.

The inner loop is our extension of GSSA that allows us to solve for bond shares of each age group and the risk-free rates of return. Here we use binary search to determine the riskfree rate $\bar{r}$ that satisfies (16). In this binary search, the evaluation of the net bond demand is achieved by using another binary search to determine the unique bond shares that satisfy the first order conditions (18).

The following is the step by step description of our algorithm.

\section{Initialization:}

- Set $\bar{z}=1$ and solve for the nonstochastic steady state asset demands of each age group without bond, $\bar{s}=\left(\bar{s}_{1}, \ldots, \bar{s}_{G-1}\right)$. Let $\left(s_{0}, z_{0}\right)=(\bar{s}, \bar{z})$ be the starting point of the simulation.

- Approximate $G-1$ asset demand functions by polynomials in the state variables: $\theta_{1}(s, z)=\phi_{1}\left(s, z ; b_{1}\right), \ldots, \theta_{G-1}(s, z)=\phi_{G-1}\left(s, z ; b_{G-1}\right)$, where $b_{1}, \ldots b_{G-1}$ are polynomial coefficients. We use degree 1 polynomials. ${ }^{4}$ To start iterations, we use the following initial guess for the coefficients: $b_{1}=\left(0,0.9,0, \ldots, 0,0.1 \bar{s}_{1}\right), \ldots, b_{G-1}=$ $\left(0,0, \ldots, 0,0.9,0.1 \bar{s}_{G-1}\right)$. Note that for all $g \in\{1, \ldots, G-1\}$, the initial $b_{g}$ is such that $\bar{s}_{g}=\phi_{g}\left(\bar{s}, \bar{z} ; b_{g}\right)$.

Outer loop:

- Take draws of the path of $z$ 's for $T$ years. We set $T$ to 640 .

- Simulate the model forward for $t=0, \ldots, T$. More precisely, at time $t$, for each age group $g$, calculate its asset demand $\theta_{g}^{(p)}$ given the current guess for the coefficients $b_{g}^{(p)}$, where the subscript $(p)$ denotes the current iteration of the outer loop. I.e., $\theta_{g, t}^{(p)}$ equals the inner product of the vector $\left(1, s_{t}, z_{t}\right)$ with the vector of coefficients $b_{g}^{(p)}$, where $s_{t}=\left(\theta_{1}^{(p)}\left(s_{t-1}, z_{t-1}\right), \ldots, \theta_{G-1}^{(p)}\left(s_{t-1}, z_{t-1}\right)\right)$. Then the state at time $t+1$ and

\footnotetext{
${ }^{4}$ Judd, Maliar, and Maliar $(2009,2011)$ recommend orthogonal polynomials, but we found no difference in results from using higher order terms.
} 
iteration $p$ is given by $\left(s_{t+1}, z_{t+1}\right)=\left(\theta_{1}^{(p)}\left(s_{t}, z_{t}\right), \ldots, \theta_{G-1}^{(p)}\left(s_{t}, z_{t}\right), z_{t+1}\right)$, where $z_{t+1}$ given $z_{t}$ is determined by $(5)$.

- Inner loop:

- Use binary search to solve (16) for $\bar{r}_{t}$, for all $t=0, \ldots, T$. To start, make an (arbitrary) initial guess for the value of $\bar{r}_{t}$.

- For all $t=0, \ldots, T$, given $\bar{r}_{t}$, for all $g=1, \ldots, G-1$, solve (18) for $\alpha_{g-1, t}$ using another binary search (evaluate the expectation in (18) using Gaussian quadrature).

- Use $\alpha_{g-1, t}$ found above for all $g$ and for all $t$ to calculate (16) and update $\bar{r}_{t}$ for all $t$.

- Note that for each age group $g$ and each state $\left(s_{t}, z_{t}\right), t=1, \ldots, T,(17)$ implies

$$
\theta_{g}\left(s_{t}, z_{t}\right)=\beta \mathrm{E}_{z}\left[\theta_{g}\left(s_{t}, z_{t}\right)\left(1+r\left(s_{t+1}, z_{t+1}\right)\right) \frac{u^{\prime}\left(c_{g+1}\left(s_{t+1}, z_{t+1}\right)\right)}{u^{\prime}\left(c_{g}\left(s_{t}, z_{t}\right)\right)}\right]
$$

for equilibrium asset demands $\theta_{g}$. Denote the right-hand-side of $(19)$ by $y_{g}\left(s_{t}, z_{t}\right)$ and evaluate the expectation using Gaussian quadrature.

- For each age group $g$, regress $y_{g}\left(s_{t}, z_{t}\right)$ on $\left(s_{t}, z_{t}\right)$ and a constant term using regularized least squares with Trikhonov regularization (see Judd, Maliar, and Maliar, 2011 for details). Denote the estimated regression coefficients by $\hat{b}_{g}^{(p)}$.

- Check for convergence: If

$$
\frac{1}{G-1} \sum_{g=1}^{G-1} \frac{1}{T} \sum_{t=1}^{T}\left|\frac{\theta_{g}^{(p-1)}\left(s_{t}, z_{t}\right)-\theta_{g}^{(p)}\left(s_{t}, z_{t}\right)}{\theta_{g}^{(p-1)}\left(s_{t}, z_{t}\right)}\right|<\epsilon
$$

end. Otherwise, for each age group $g$ update the coefficients as $b_{g}^{(p+1)}=(1-\xi) b_{g}^{(p)}+$ $\xi \hat{b}_{g}^{(p)}$ and return to the beginning of the outer loop. We use $\xi \in[0.01,0.2]$ and $\epsilon \in$ $\left[10^{-10}, 10^{-13}\right]$. 
Deviations from Euler Equations

\begin{tabular}{|c|c|c|c|c|c|c|c|}
\hline \multirow[b]{2}{*}{ Y } & \multicolumn{4}{|c|}{ Model } & \multicolumn{3}{|c|}{ Mean Absolute Euler Eq. Deviations } \\
\hline & Policy & Bond & Technology & Depreciation & Min & Mean & $\operatorname{Max}$ \\
\hline \multicolumn{8}{|c|}{ 80-Period Models } \\
\hline 2 & None & No & $\mathrm{AR}(1)$ & No & 0.00006 & 0.00019 & 0.00074 \\
\hline 2 & Fixed & No & $\operatorname{AR}(1)$ & No & 0.00013 & 0.00039 & 0.00210 \\
\hline 2 & Variable & No & $\operatorname{AR}(1)$ & No & 0.00008 & 0.00037 & 0.00085 \\
\hline 2 & Proportional & No & $\operatorname{AR}(1)$ & No & 0.00014 & 0.00026 & 0.00099 \\
\hline 5 & None & No & $\operatorname{AR}(1)$ & No & 0.00014 & 0.00056 & 0.00233 \\
\hline 2 & None & No & Rare Disasters & No & 0.00025 & 0.00081 & 0.00309 \\
\hline \multicolumn{8}{|c|}{ 40-Period Models } \\
\hline 2 & None & No & $\mathrm{AR}(1)$ & No & 0.00010 & 0.00037 & 0.00058 \\
\hline 2 & None & Yes & $\operatorname{AR}(1)$ & No & 0.00024 & 0.00037 & 0.00059 \\
\hline 2 & None & No & Rare Disasters & No & 0.00035 & 0.00119 & 0.00185 \\
\hline 2 & None & Yes & Rare Disasters & No & 0.00087 & 0.00309 & 0.00648 \\
\hline \multicolumn{8}{|c|}{ 20-Period Models } \\
\hline 2 & None & No & $\operatorname{AR}(1)$ & No & 0.00017 & 0.00066 & 0.00088 \\
\hline 2 & None & Yes & $\operatorname{AR}(1)$ & No & 0.00043 & 0.00049 & 0.00070 \\
\hline 2 & Variable & No & $\operatorname{AR}(1)$ & No & 0.00012 & 0.00047 & 0.00158 \\
\hline 2 & Variable & Yes & $\operatorname{AR}(1)$ & No & 0.00111 & 0.00462 & 0.00761 \\
\hline 15 & None & No & $\operatorname{AR}(1)$ & No & 0.00576 & 0.02147 & 0.04999 \\
\hline 15 & None & Yes & $\operatorname{AR}(1)$ & No & 0.00989 & 0.01377 & 0.02865 \\
\hline 6 & None & No & Rare Disasters & No & 0.00748 & 0.01982 & 0.03055 \\
\hline 6 & None & Yes & Rare Disasters & No & 0.00548 & 0.00641 & 0.01002 \\
\hline 2 & None & No & Random Walk & No & 0.00250 & 0.01367 & 0.02357 \\
\hline 2 & None & No & $\operatorname{AR}(1)$ & Stochastic & 0.00234 & 0.01351 & 0.02799 \\
\hline
\end{tabular}

Table 1: Minimum, mean, and maximum across generations of the average, across time, of the absolute value of the generation-specific, out-of-sample deviations from the perfect satisfaction of Euler equations.

\subsection{Out-of-Sample Deviations from the Perfect Satisfaction of Eu- ler Equations}

Note that in our 640-period sample the generation-specific Euler equations (18) hold almost perfectly by construction. A satisfactory solution requires they hold out of sample as well. Hence, to test the accuracy of solutions, for each model considered we draw a fresh sequence of $z$ 's that is 10 times longer than the 640-period sequence used in the original simulation. We then simulate the model forward on the new path of $z$ 's, using the original asset demand functions, $\theta_{g}$, and, in the case of bonds, clearing the bond market by rerunning the inner loop. We calculate the out-of-sample percentage deviations from full satisfaction of the Euler equations,

$$
\epsilon(s, z)=\left[\frac{\beta \mathrm{E}_{z}\left[\left(1+r\left(s^{\prime}, z^{\prime}\right)\right) u^{\prime}\left(c_{g+1}\left(s^{\prime}, z^{\prime}\right)\right)\right]-u^{\prime}\left(c_{g}(s, z)\right)}{u^{\prime}\left(c_{g}(s, z)\right)}\right] \times 100
$$

for each period in the newly simulated time path and for each generation $g \in 1, \ldots, G-1 .^{5}$ Finally, we compute the average, across time, of the absolute value of the deviations from Eu-

\footnotetext{
${ }^{5}$ The out-of-sample test does not apply to (18) since the inner loop is rerun, i.e. (18) will hold by construction.
} 
ler equations for each generation. Table 1 reports the summary statistics, across generations, of their average absolute deviations from Euler equations for each model considered. ${ }^{6}$

Deviations tend to be larger in cases with high risk aversion, rare disaster, or bonds. The worst preforming model is the 20-period model with very high risk aversion $(\gamma=15)$ and no bonds, where the cross-generation mean and maximum of the generation-specific timeaverages of absolute Euler equation deviations are 2 percent and 5 percent, respectively. In most other models, deviations are at least an order of magnitude smaller.

\section{Results}

\subsection{0-Period Models Without Bonds}

\subsubsection{Rates of Return and Wages}

Figure 1 presents the evolution over 640 years of the capital stock, output, the rate of return, and the wage. These results are from our main model, which features 80 periods, no bonds, a risk aversion coefficient $\gamma$ equal to 2, and no rare disasters. Each panel displays results for three cases - no policy, fixed policy, and variable policy.

Total factor productivity across the 640 years has a mean of 0.9987 and a standard deviation of 0.0313 . This produces sizeable fluctuations in capital, output, the rate of return, and the wage, with standard deviations of 36.67, 4.67, 0.0013, and 0.070 around means of 1345, 129, 0.038, and 1.93.

Figure 1's main message is the secular impact of generational policy. ${ }^{7}$ Where the economy finds itself in the future is primarily the function of what the government does to it. Here the policies are taking from the young, who are saving for their retirement, and giving to the old, who are spending in light of their approaching deaths. This redistribution from savers to spenders produces a sizable crowding out of the national saving. Given the closure of the economy, domestic investment falls pari passus. With fixed (variable) policy, the average capital stock falls by 34.12 (33.30) percent, producing a 12.92 (12.53) percent long-term decline in both average output and average wage and a 32.64 (31.31) percent increase in the average rate of return.

\footnotetext{
${ }^{6}$ Note, these deviations are not Euler errors which capture differences in period $t$ 's marginal utility and period $(t+1)$ 's realized marginal utility (properly weighted by $\beta$ and $r\left(s^{\prime}, z^{\prime}\right)$ ). Rather, they reference the discrepancy in period $t$ between the marginal utility and its properly weighted expectation.

${ }^{7}$ Proportional policy, which strikes middle ground between fixed and variable policies, is not plotted in this and subsequent figures to avoid clutter, but its effect on generational risk is analyzed in Sections 6.1.4 and 7.3.
} 

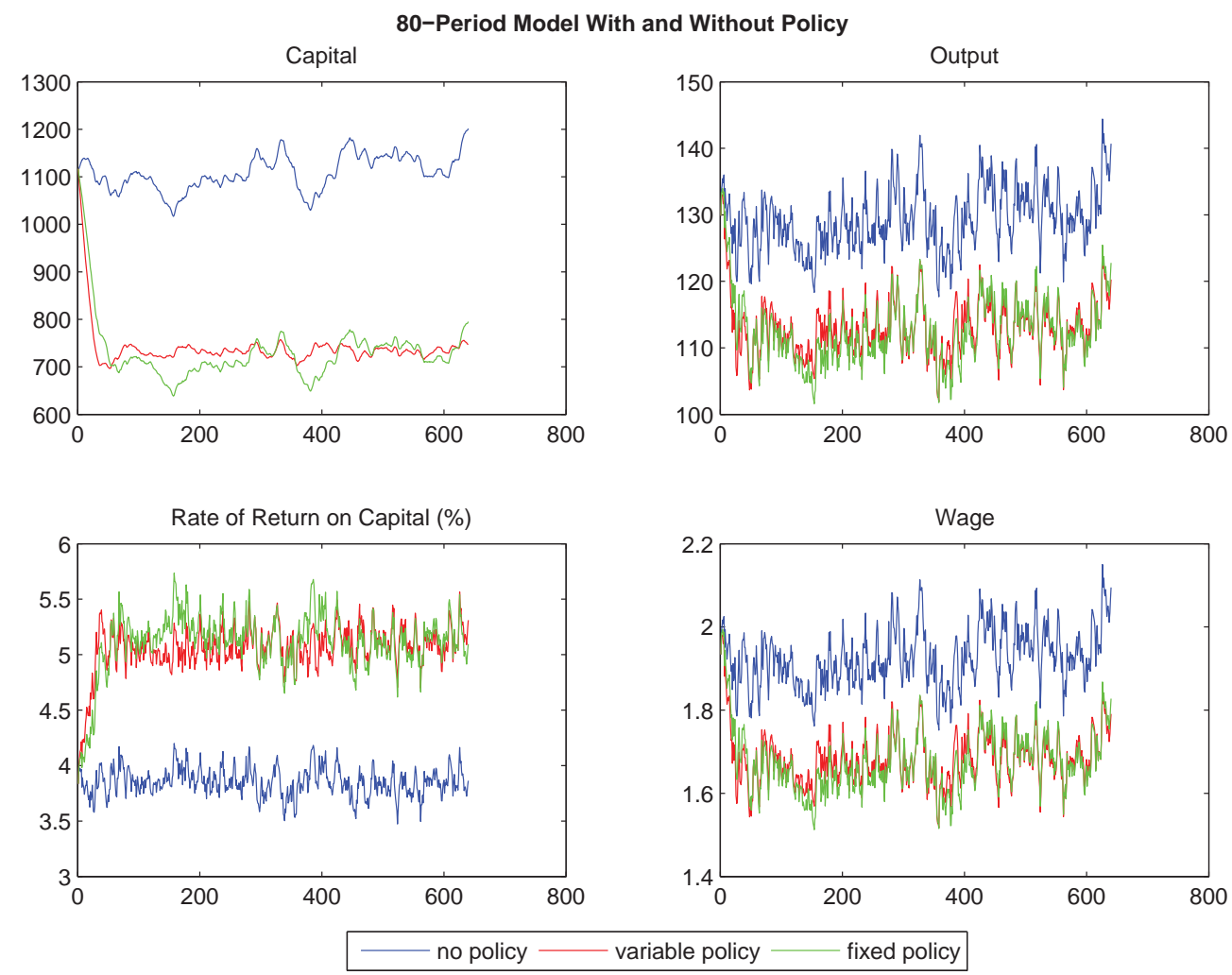

Figure 1: Capital, output, rate of return on capital, and wage rates in the 80-period model with and without policies.

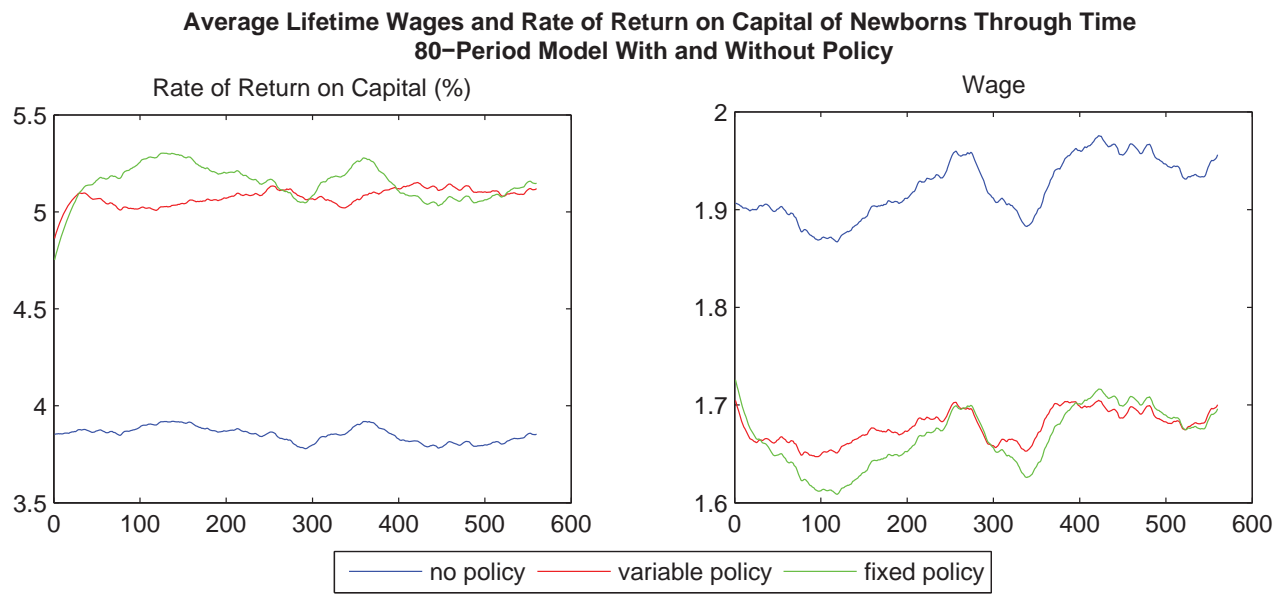

Figure 2: Average lifetime rates of return on capital and wage rates of newborns born in specified year in the 80-period model with and without policies. 
Despite the annual variability in both $z$ and $K$, Figure 2 reveals little variability in average lifetime rates of return on capital and wage rates of newborns. For the rates of return on capital in the no policy, fixed policy, and variable policy simulations, the standard deviation is $0.00038,0.00092$, and 0.00043 , around means of $0.039,0.052$, and 0.051 . For the wage rates, the standard deviation is $0.03,0.03$, and 0.016 around means of $1.92,1.67$, and 1.68 for the three models respectively. This suggests that the lifetime risks newborns face may not vary as much as macroeconomic fluctuations might lead us to believe. Moreover, given the longevity of households, there may be significant scope for self-insurance by pooling risks over time.

\subsubsection{Consumption and Asset Demands}
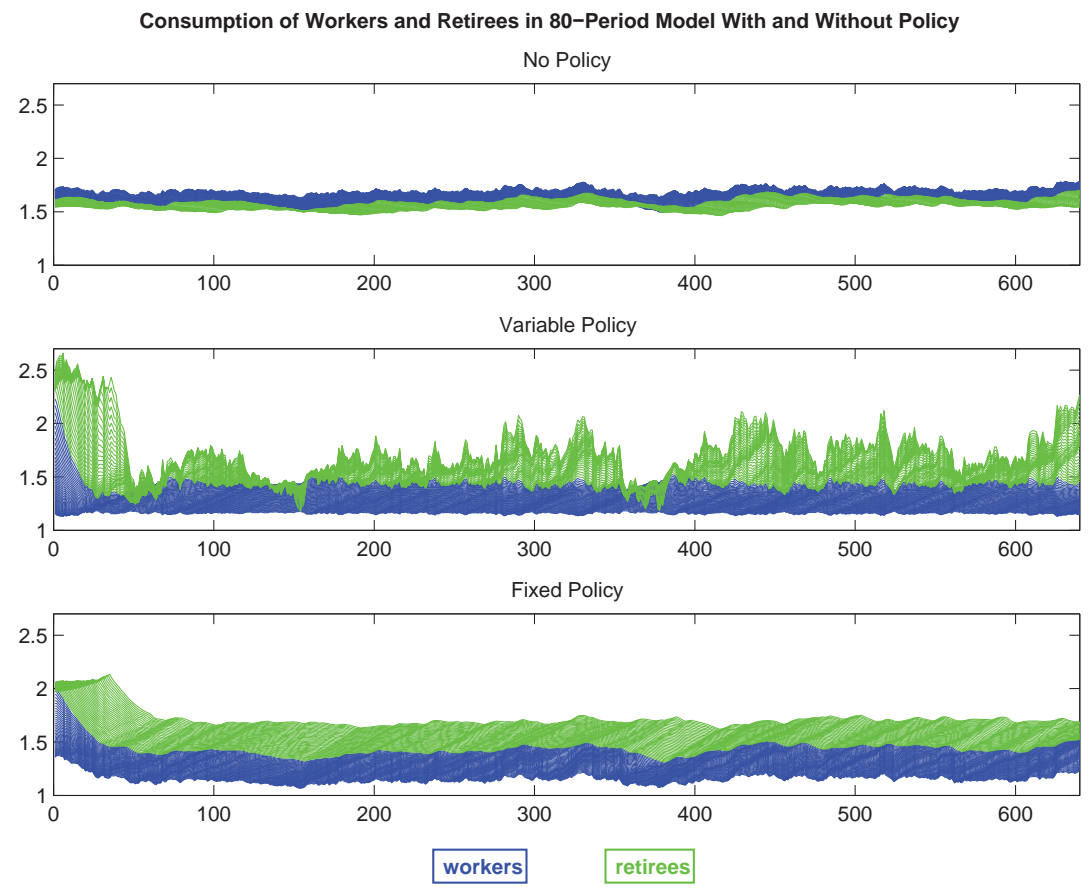

Figure 3: Consumption of workers and retirees through time in the 80-period model with and without policies.

Figure 3 plots annual consumption levels through time of the 45 working age groups (in blue) and those of the 35 retired age groups (in green) without and with fixed and variable policies. In each year there are 45 blue points being plotted, reflecting the consumption of the 45 workers (from youngest to oldest) in that year, and 35 green points, reflecting the consumption of retirees (from youngest to oldest). 
With no policy, workers consume somewhat more than retirees, and the variability of consumption is similar for the two groups. Note that there is little difference across time in the general level of consumption of either workers or retirees or in the spread of consumption among workers or among retirees.

As the next two panels illustrate, once policy is introduced, workers, on average, consume less than retirees as they change their desired longitudinal age-consumption profile in light of the higher rate of return on capital. Moreover, there is more variability in consumption levels among both workers and retirees at a point in time and, in the case of variable policy, across time for retirees. These charts suggest that government policy can exacerbate generational risk.

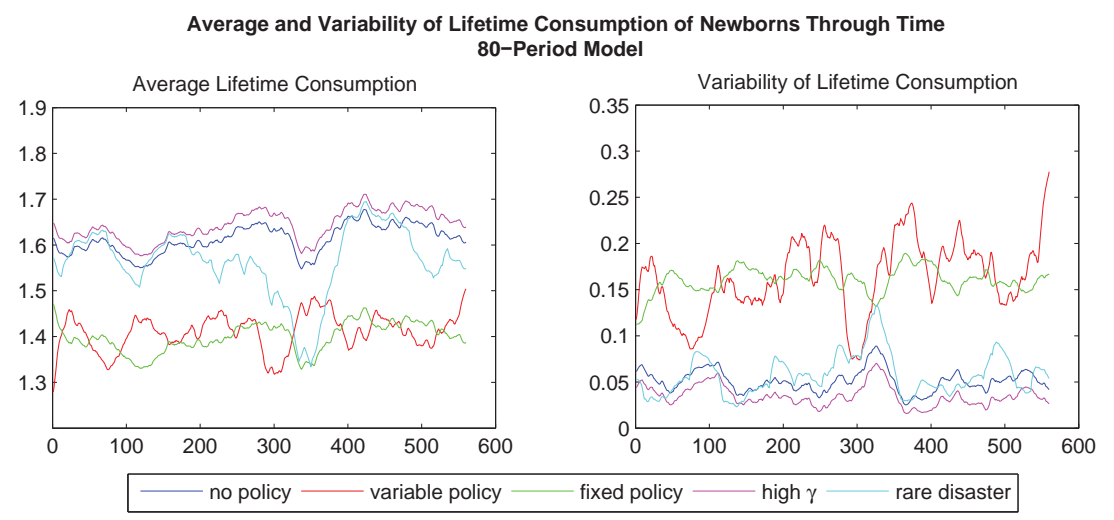

Figure 4: Average lifetime consumption and variability of lifetime consumption (standard deviation of an age group's consumption over its lifetime) of newborns through time in the 80-period model with and without policies. In models labeled "no policy", "variable policy", and "fixed policy" the risk aversion is 2 and there are no rare disasters; in the model labeled "high gamma" the risk aversion is 5 and there are no rare disasters; in the model labeled "rare disaster", the risk aversion in 2, the probability of disaster in 3 percent per year, and contraction size during the disaster is 20 percent.

Figure 4 shows the downside of the intergenerational redistribution. It charts average lifetime consumption of successive new generations, referenced as newborns. This average is both lower and more volatile with policy than without. The lower average is not surprising as each new generation can expect to a) pay more when young than it receives when old in a present value sense and b) experiences lower real wages over its lifetime thanks to capitals crowding out. Of particular interest is the volatility of lifetime consumption when the generational policies, especially the variable policy, are introduced. Again we see the take-as-you-go policies exacerbating, not mitigating age group differences in realized lifetime 
consumption.

The figure also considers high and low risk aversion as well as occasional rare disasters. In the long run, increasing the risk aversion increases the average and lowers the volatility of lifetime consumption as it leads to more capital accumulation and higher wages. In the rare disaster case the opposite is true as some of the economy's production potential is periodically wiped out.
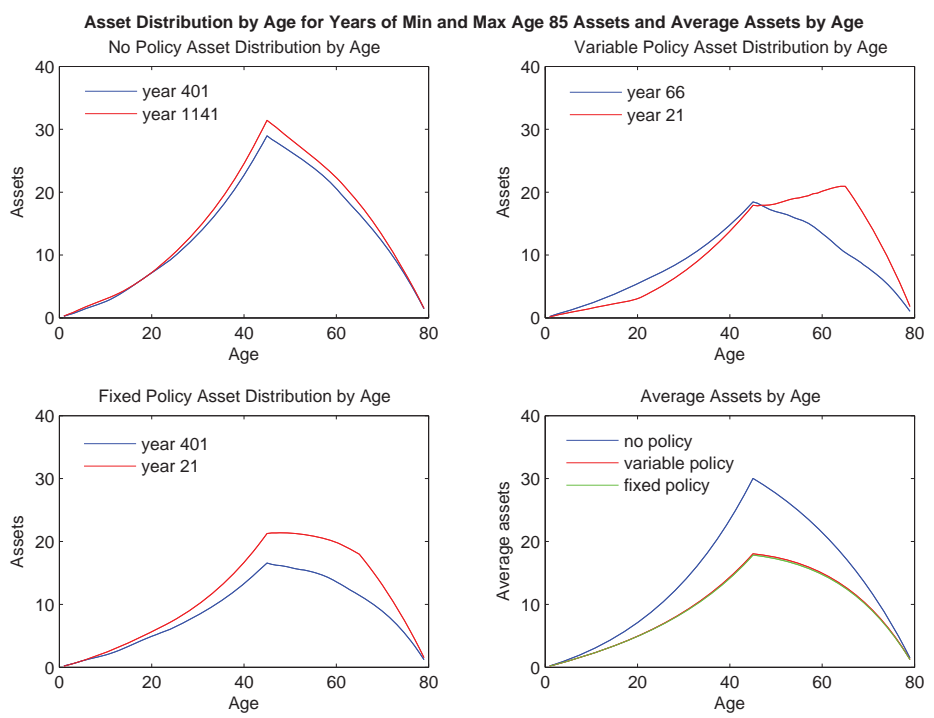

Figure 5: Asset distribution by age for years of minimum and maximum age 85 assets, and average assets by age in the 80-period model with and without policies.

Figure 5 plots the age-asset distribution for the two years when the 85-year-olds have the smallest and largest amounts of assets. We see the typical life-cycle pattern of asset accumulation in working years and decumulation in retirement. The change in the shape of the age-asset profile with the take-as-you-go policies is as expected, with less private wealth accumulation when young and slower decumulation when old thanks to the infusion of government receipts. Although comparison of Figure 5's upper-right and lower-left panels suggests that the shape of the asset distribution is systematically very different in the case of variable versus fixed policy, this is not the case. The lower-right panel shows that, on average, the age-asset profiles are virtually indistinguishable under the two policies.

\subsubsection{Utility Measures of Generational Risk}

In Figure 6 and the associated Table 2 we consider more formal measures of generational risk, which we call expected and realized lifetime utility measures. 


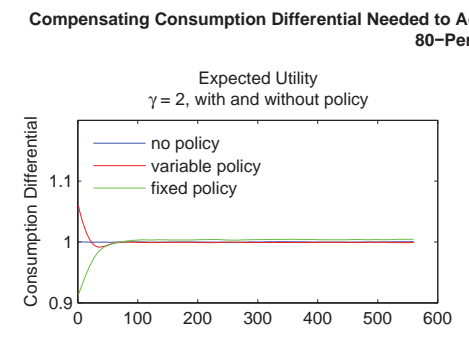

80-Period Model
8chieve Average
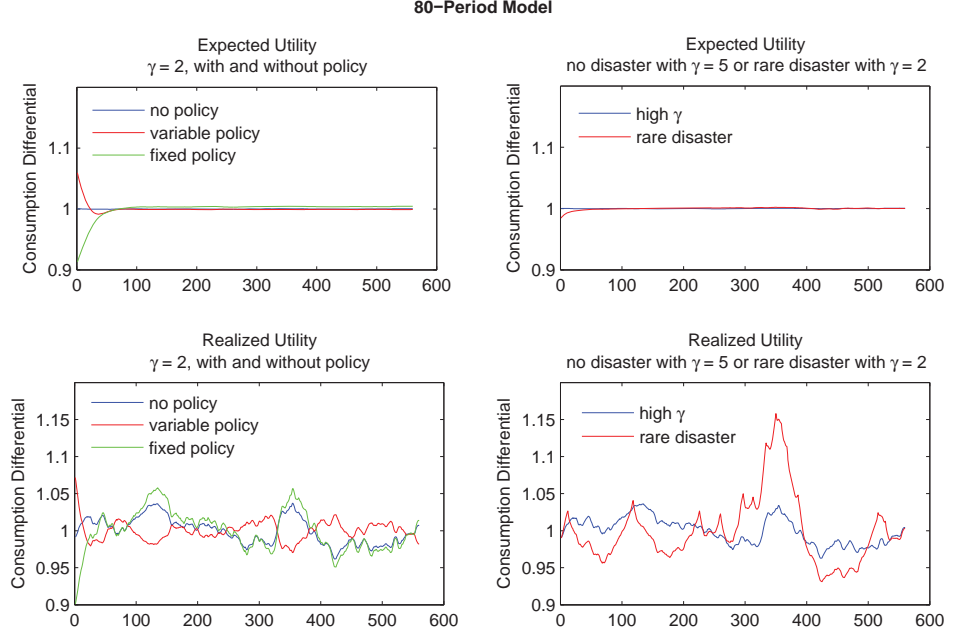

Figure 6: Expected and realized utility measures of generational risk in the 80-period benchmark model with and without policy, and two of its variants. In models labeled "no policy", "variable policy", and "fixed policy" the risk aversion is 2 and there are no rare disasters; in the model labeled "high gamma" the risk aversion is 5 and there are no rare disasters; in the model labeled "rare disaster", the risk aversion in 2, the probability of disaster in 3 percent per year, and contraction size during the disaster is 20 percent. The realized (expected) measure of generational risk is defined as the variability of the compensating consumption differential of newborns through time needed to achieve the average realized (expected) utility of newborns. 
Each newborn's expected lifetime utility measure is defined as the compensating consumption differential needed to achieve the average (expected) lifetime utility across newborns. To compute the differential for, say, the age group born in year $x$, we first calculate the average realized lifetime utility of generation $x$ across 5,000 different paths of draws of the productivity shock. Call this $E U_{x}$. Next, we divide the average of $E U_{t}$ over all $t$ from time 0 to 640 by $E U_{x}$ and raise the ratio to the power $1 /(1-\gamma)$. The result is the factor by which consumption of generation $x$ needs to be multiplied in all possible states it might experience to achieve the same lifetime utility, on average, as other generations enjoy. The closer are the consumption differentials to 1, and the less variable they are through time, the less difference does the date of birth make for the household's expected lifetime utility, i.e. the smaller is the generational risk. Given the stationary nature of the model, the expected lifetime utility differentials should be very small except for generations born while the policies are being introduced and the economy is heading toward its new stochastic steady state (ergodic distribution).

The realized utility measure is based on the particular state the generation is born into and the particular sequence of productivity shocks drawn over its lifetime. We first calculate each generation's particular realized lifetime utility and form the average of these realized values across all generations born between years 0 and 640. Next, we calculate for each generation the factor by which we need to multiply each year's realized consumption to produce the same realized lifetime utility as the first 640 generations experience on average.

\begin{tabular}{lcccr}
\multicolumn{1}{c}{ Coefficients of Variation (in Percent) of Expected and Realized Generational Risk Measures } \\
\hline Model & $\begin{array}{c}\text { Expected utility } \\
\text { measure CV (\%) } \\
\text { full sample }\end{array}$ & $\begin{array}{c}\text { Realized utility } \\
\text { measure CV (\%) } \\
\text { full sample }\end{array}$ & $\begin{array}{c}\text { Expected utility } \\
\text { measure CV (\%) } \\
\text { drop 1 } \mathbf{1 5}^{\text {st }} \mathbf{7 5} \text { periods }\end{array}$ & $\begin{array}{c}\text { Realized utility } \\
\text { measure CV (\%) } \\
\text { drop 1 } \mathbf{1}^{\text {st }} \mathbf{7 5} \text { periods }\end{array}$ \\
no policy & 0.03 & 1.76 & 0.03 & 1.83 \\
variable policy & 0.64 & 1.26 & 0.02 & 1.08 \\
fixed policy & 1.34 & 2.70 & 0.06 & 2.58 \\
high gamma & 0.02 & 1.77 & 0.02 & 1.85 \\
rare disaster & 0.20 & 4.59 & 0.08 & 4.82 \\
\hline
\end{tabular}

Table 2: Coefficients of variation of the expected and realized utility measures of generational risk in the 80-period models presented in Figure 6.

The left-hand-side panels of Figure 6 plot these two measures for our main model without and with government policies. The right-hand side panels consider high risk aversion and rare disaster versions of the model. Table 2 shows the corresponding coefficients of variation, in percentage points, computed using both the entire data samples plotted in Figure 6, and the subsamples obtained by removing the first 75 observations from each time-series. 
For all models and both generational risk measures, realized lifetime consumption differentials are close to 1 and vary very little though time. Generational risk is, as expected, smaller (the consumption differentials are closer to 1) under the expected utility measure than under the realized utility measure.

The first two columns of Table 2, where all 640 years are considered, suggest that the government policies exacerbate generational risk. But some of this risk arises from being born either during or after the policies are fully infused in the economy's general equilibrium. The last two columns leave out the first 75 years, but they still show the policies worsening generational risk. Even so, there is not much generational risk to either be shared or worsened. Nor does high risk aversion or rare disasters change this story much.

\subsubsection{Consumption Co-movement Measures of Generational Risk}

\begin{tabular}{|c|c|c|c|c|c|c|c|c|c|}
\hline & \multicolumn{3}{|c|}{ No Policy } & \multicolumn{3}{|c|}{ High $y$} & \multicolumn{3}{|c|}{ Rare Disaster } \\
\hline & Min & Mean & $\operatorname{Max}$ & Min & Mean & $\operatorname{Max}$ & Min & Mean & $\operatorname{Max}$ \\
\hline$\rho\left(\% \Delta\right.$ in C worker,$\% \Delta$ in C worker $\left._{j}\right)$ & 0.973 & 0.998 & 1.000 & 0.983 & 0.999 & 1.000 & 0.917 & 0.994 & 1.000 \\
\hline$\rho\left(\% \Delta\right.$ in Cretiree $_{i}, \% \Delta$ in Cretiree $\left._{j}\right)$ & 0.865 & 0.986 & 1.000 & 0.840 & 0.986 & 1.000 & 0.641 & 0.955 & 1.000 \\
\hline$\rho\left(\% \Delta\right.$ in $C$ agent $_{1}, \% \Delta$ in $C$ agent $)$ & 0.785 & 0.963 & 1.000 & 0.840 & 0.987 & 1.000 & 0.637 & 0.934 & 1.000 \\
\hline$\rho\left(\% \Delta\right.$ in $C$ agent $t_{1}, \% \Delta$ in per capita $\left.C\right)$ & 0.822 & 0.975 & 0.997 & 0.863 & 0.991 & 0.996 & 0.682 & 0.958 & 0.993 \\
\hline \multirow[t]{2}{*}{ all agents: absolute $\%$ adjustment } & 0.000 & 0.191 & 0.855 & 0.000 & 0.163 & 0.814 & 0.000 & 0.250 & 2.903 \\
\hline & \multicolumn{3}{|c|}{ Fixed Policy } & \multicolumn{3}{|c|}{ Variable Policy } & \multicolumn{3}{|c|}{ Proportional Policy } \\
\hline$\rho\left(\% \Delta\right.$ in C worker,$\% \Delta$ in C worker $\left.{ }_{j}\right)$ & 0.886 & 0.993 & 1.000 & -0.986 & 0.465 & 1.000 & 0.984 & 0.999 & 1.000 \\
\hline$\rho\left(\% \Delta\right.$ in Cretire $_{i}, \% \Delta$ in C retiree $\left._{j}\right)$ & 0.618 & 0.957 & 1.000 & 0.995 & 0.999 & 1.000 & 0.953 & 0.994 & 1.000 \\
\hline$\rho\left(\% \Delta\right.$ in C a gent ${ }_{i}, \% \Delta$ in $C$ agent $)$ & 0.330 & 0.874 & 1.000 & -0.989 & 0.008 & 1.000 & 0.953 & 0.993 & 1.000 \\
\hline$\rho\left(\% \Delta\right.$ in $C$ agent $t_{1}, \% \Delta$ in per capita $\left.C\right)$ & 0.394 & 0.904 & 0.995 & -0.988 & 0.065 & 0.985 & 0.967 & 0.989 & 0.992 \\
\hline all agents: absolute $\%$ adjustment & 0.000 & 0.513 & 1.815 & 0.000 & 1.015 & 9.684 & 0.000 & 0.496 & 1.279 \\
\hline
\end{tabular}

Table 3: Measures of generational risk in the 80-period models: summary statistics of pairwise correlations in percentage changes in consumption among different age groups, and absolute percentage adjustments needed to achieve full risk sharing. The first 75 observations (i.e. the capital stock transition period after the policies are introduced) have been dropped from all calculations.

Abel and Kotlikoff (1988) show that full risk sharing among contemporaneous generations, indeed all agents, with the homothetic preferences considered here requires equal percentage changes in the consumption from one period to the next. Hence, one can measure the extent of generational risk by considering the co-movement of consumption across age groups as well as the extent of consumption adjustments that would be needed to achieve perfect consumption co-movement.

Table 3 considers such measures. ${ }^{8}$ First, it reports summary statistics of pairwise correlations in annual percentage changes in consumption between different age groups among

\footnotetext{
${ }^{8}$ Values of 0.000 and 1.000 reflect rounding.
} 
workers only, retirees only, and all agents. ${ }^{9}$ Second, it examines the correlation of each agent's annual percentage change in consumption with the annual percentage change in per capita consumption. Third, it summarizes the agent- and year-specific absolute percentage consumption adjustment needed to achieve perfect risk sharing, i.e. to ensure that all agents experience the same percentage change in the year in question.

The first four rows of the no policy, rare disaster, and high $\gamma$ panels of Table 3 show that the average correlations considered in the first and second consumption co-movement measures exceed 0.934. Indeed, the smallest correlation coefficient of any agent's consumption with per capita consumption in these three panels is 0.682 . The corresponding values in the fixed policy panel are slightly lower — at least 0.874 for the average consumption co-movement measures, and exceeding 0.394 for the co-movement with per capita consumption measurewhile in the proportional policy panel the corresponding values are slightly higher - 0.993 and 0.967. The fifth row of these five panels shows that the average (across agents) absolute percentage adjustments needed to achieve full risk sharing are less than 1 percent in all cases, ranging from a low of 0.163 in the high $\gamma$ case to a high of 0.513 percent in the fixed policy case. Hence, generational risk in the absence of generational policy is tiny according to all three measures.

The variable policy panel of Table 3 paints a different picture. It shows that pairwise correlations in percentage changes in consumption among some workers are highly negative. This is not surprising since variable policy is modeled intentionally to be countercyclical, i.e. to turn good times for workers into bad times as the increase (decrease) in taking exceeds the increase (decrease) in the gross wage.

The youngest workers are hurt the most for two reasons. First, the current high taking implies likely high takings in the near future due to persistence in total factor productivity $(z)$. Second, they still have a long time to wait before they can benefit from high giving and increased asset income in retirement. On the other hand, for the oldest workers high taking in good times is offset by both the expectation of future high giving and higher asset returns (due to the persistence in the $z$ 's). Hence, one would expect the correlation in percentage changes in consumption to be the lowest between the youngest and the oldest of workers. Indeed, the minimum correlation of -0.986 occurs between the youngest (1-year-old) and the oldest (45-year-old) workers. Moreover, the larger is the distance in the workers' age, the lower is the correlation in their percentage changes in consumption. ${ }^{10}$

\footnotetext{
${ }^{9}$ For each age group $g$, we compute that age group's percentage change in consumption between $t$ and $t-1,\left(c_{g, t}-c_{g-1, t-1}\right) / c_{g-1, t-1}$, for all $t$. We then correlate the percentage change in consumption time series for any pair of age groups.

${ }^{10}$ This trend can be seen easily as follows. Find, for each worker $i$, that worker, $j$, whose percentage change in consumption is least correlated with that of $i$. Then relate those correlations to the distance in
} 


\subsubsection{Examining the Krusell-Smith Approximation}

We next conduct an experiment to examine Krusell and Smith's (1998) contention that a summary statistic of the wealth distribution, particularly average asset holdings, is a sufficient descriptor of the full state space. The experiment relies on our derived age-specific consumption functions whose arguments, recall, are the individual asset holdings of all 80 generations as well as the current productivity shock. Specifically, we ask whether reshuffling the assets holdings between the young and the old significantly alters individual and aggregate consumption holding fixed the asset holdings of the age group itself. The reshuffling for an agent age $g$ entails starting with the assets of the oldest group that's not age $g$ and exchanging the asset with those of the youngest agent that's not age $g$ and proceeding in this fashion to the assets of the next oldest and next youngest agents not age $g$. If evaluating each age group's consumption with this reshuffling of the values of the arguments of the function (apart from the value of the age group's own assets) produces major differences in predicted consumption, then who holds the assets, not just their average value, matters.
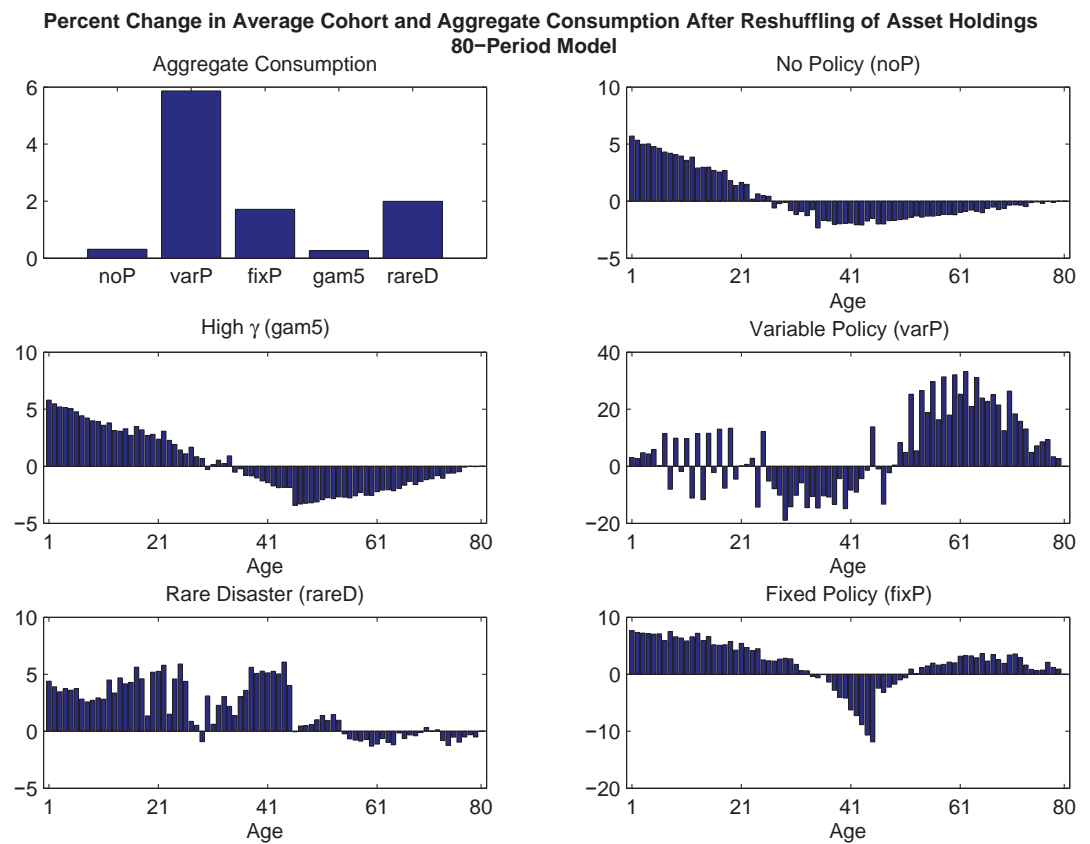

Figure 7: Examining the Krusell-Smith approximation: average percentage changes in agegroup-specific and aggregate consumption in the 80-period models after reshuffling of asset distributions.

Figure 7 shows the average (across 640 years) difference between the recomputed and the age between $i$ and $j$. 
original consumption as a percentage of the original consumption for each of our 80-period models under consideration. The top-left panel does this for aggregate consumption and the rest of the panels for age-group-specific consumption.

Consider first aggregate consumption. The reshuffling of assets makes little difference in our base case, no-policy model. But with variable policy, there is a roughly 6 percent increase in average annual consumption, which is major. Even the roughly 2 percent increase in average annual consumption with fixed policy and no policy, but rare disasters is sizeable when one considers how such a consumption differential would affect the economy's capital formation through time. Moreover, reshuffled values of average annual aggregate consumption obscure large variations across the years. Across all 640 years, the maximum increase in aggregate consumption from reshuffling is 9.923 percent, while the minimum is 0.263 percent. This suggests that the Krusell-Smith algorithm is inadequate in our life-cycle setting.

Why does aggregate consumption rise with the reshuffling? As the three no-policy panels show, consumption of the young increases and that of the old declines. This is not surprising since the reshuffling scheme puts more assets in the hands of the young. This ensures that the assets will be around longer in the economy, and that wage rates will be higher and rates of return lower for many years to come. For workers, the reshuffling raises their lifetime resources as perceived by their consumption functions leading to an unambiguous rise in their consumption. For retirees, the reshuffling leaves their own assets unchanged, but lowers their perceived future rates of return. But their consumption is driven primarily by their own holdings of assets, not by the return on their assets. Hence, it's not surprising that the collective consumption of retirees falls by less than the collective consumption of the young and that aggregate consumption rises.

Note also that, other things equal, the impact of reshuffling on aggregate consumption is greater in the models with policies. The reason is clear. The capital stock is smaller in these models, meaning that the derivative of the wage with respect to the capital stock is larger. Hence, a small expected change in the economy's implied future capital stock has a larger impact on the future expected wage and thus a larger influence on the consumption of workers.

For individual agents at specific ages the reshuffling makes a big difference for all models under consideration. Indeed, in the case of variable policy the percentage change in consumption at certain older ages caused by the reshuffling averages close to 30 percent. Interestingly, the two policies produce different age-specific reactions to the reshuffling indicating the importance of the policy regime for underlying consumption behavior. In fact, with variable policy, the elderly now end up consuming considerably more when assets are 
reshuffled reflecting the fact that having assets last longer in the economy means higher wages and, therefore, receiving higher gettings, on average, each year from the young. The elderly's consumption is also somewhat higher, on average, when the policy involves fixed taking. This may reflect the higher value, in a present value sense, arising from the fixed annual receipts being implicitly discounted at a lower time path of asset returns. ${ }^{11}$

\subsection{Models With Bonds}

In Table 4 and Figures 8-10 we consider 40-period models with a one-period risk-free bond, risk aversion of 2 , and with and without rare disasters.

\subsubsection{0-Period Model: Consumption Co-movement Measures of Generational Risk}

\begin{tabular}{|c|c|c|c|c|c|c|c|c|c|c|c|c|}
\hline \multicolumn{13}{|c|}{ Correlation Measures of Generational Risk, 40-Period Model with $\gamma=2$} \\
\hline & \multicolumn{3}{|c|}{$\begin{array}{l}\text { No Disaster } \\
\text { No Bond }\end{array}$} & \multicolumn{3}{|c|}{$\begin{array}{l}\text { No Disaster } \\
\text { With Bond }\end{array}$} & \multicolumn{3}{|c|}{$\begin{array}{l}\text { Rare Disaster } \\
\text { No Bond }\end{array}$} & \multicolumn{3}{|c|}{$\begin{array}{c}\text { Rare Disaster } \\
\text { With Bond }\end{array}$} \\
\hline & Min & Mean & Max & Min & Mean & Max & Min & Mean & Max & Min & Mean & Max \\
\hline$\rho\left(\% \Delta\right.$ in $\mathrm{C}$ worker $_{i}, \% \Delta$ in C worker $\left._{j}\right)$ & 0.990 & 0.999 & 1.000 & 0.999 & 1.000 & 1.000 & 0.980 & 0.998 & 1.000 & 0.911 & 0.988 & 1.000 \\
\hline$\rho\left(\% \Delta\right.$ in C retiree $_{i}, \% \Delta$ in $\left.\mathrm{C}_{\text {retiree }}\right)$ & 0.986 & 0.996 & 1.000 & 0.999 & 1.000 & 1.000 & 0.924 & 0.984 & 1.000 & 0.970 & 0.993 & 1.000 \\
\hline$\rho\left(\% \Delta\right.$ in $C$ agent $_{i}, \% \Delta$ in $\mathrm{C}$ agent $\left._{j}\right)$ & 0.917 & 0.981 & 1.000 & 0.997 & 0.999 & 1.000 & 0.869 & 0.968 & 1.000 & 0.786 & 0.966 & 1.000 \\
\hline 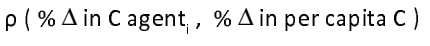 & 0.942 & 0.987 & 0.997 & 0.998 & 0.999 & 0.999 & 0.911 & 0.979 & 0.994 & 0.939 & 0.981 & 0.998 \\
\hline all agents: absolute $\%$ adjustment & 0.347 & 1.495 & 2.656 & 1.318 & 1.493 & 1.658 & 0.015 & 1.523 & 5.595 & 0.001 & 1.517 & 4.336 \\
\hline
\end{tabular}

Table 4: Measures of generational risk in the 40-period models with and without rare disasters: summary statistics of pairwise correlations in percentage changes in consumption among different age groups, and absolute percentage adjustments needed to achieve full risk sharing.

Table 4 shows our three consumption co-movement measures of generational risk with and without bonds. In all cases, average consumption co-movement correlation coefficients are very high, ranging from a low of 0.966 in the case of rare disasters and bond to a high of 0.999 in the case of no disasters and bond. The absolute percentage adjustments average about 1.5 percent in all cases.

These results confirm that generational risk, even with rare disasters, is small. Although a bond market reduces the range of adjustments needed to achieve full risk sharing, it makes no difference to the mean.

\footnotetext{
${ }^{11}$ Since there is, in our base-case model, no term structure of interest rates, not even a short-term bond market, the model involves no explicit discounting of future non-asset income flows.
} 


\subsubsection{0-Period Model: Bond Demands and the Equity Premium}

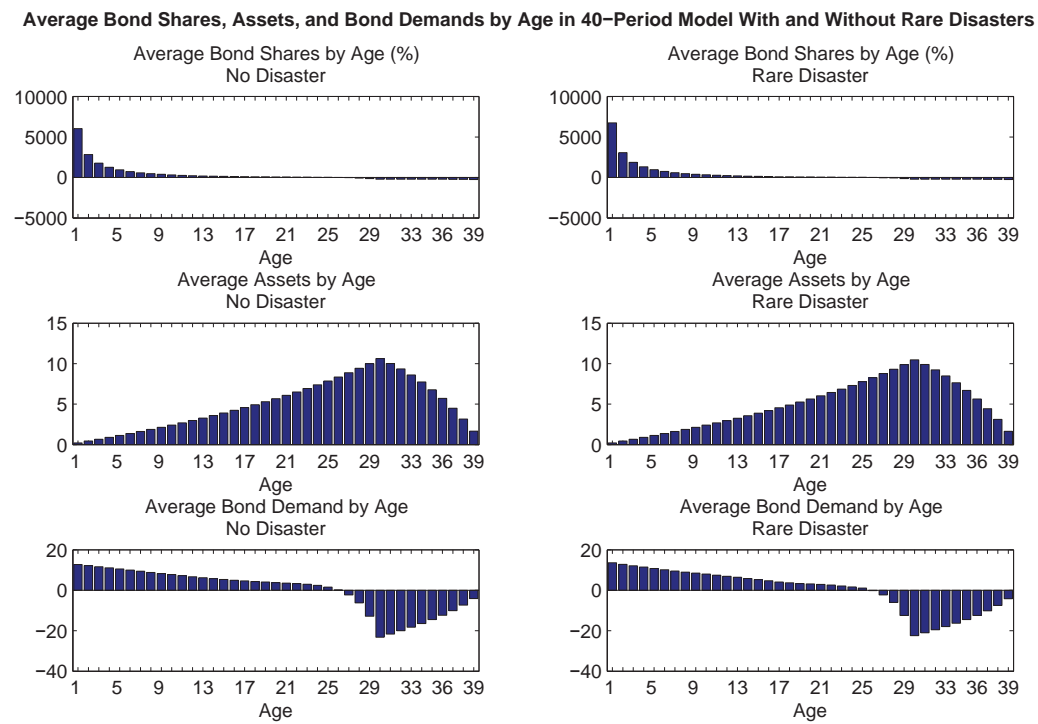

Figure 8: Average bond shares, assets, and bond demands by age in the 40-period model with risk aversion of 2 , with and without rare disasters. In the case of rare disasters, the probability of disaster in 1.7 percent per year, and contraction size during the disaster is 20 percent.

Figure 8 plots age-specific average bond shares, assets, and bond demands. It shows that the young are the demanders of bonds, the youngest most so, and that the old are the suppliers. The figure also shows that rare disasters make no material difference to average bond demands.

The age pattern of bond holdings is intuitive since the young mainly live off of uncertain wage income. On the other hand, the old live off the assets they have accumulated and the income earned on these assets. But while the return on assets is uncertain, the principal cannot be lost and, thus, is safe. Consequently, the old are in a position to insure the young against productivity shocks by selling bonds to the young and going long capital (stocks).

The counterpart of the old going long in stocks and short in bonds is that the young go short in stocks and long in bonds. Indeed, the youngest of the young hold close to an astounding 6,000 percent of their assets in bonds. But since their assets are themselves small, their absolute holding of bonds is reasonable.

To see this, note that the young short stocks to insure against an adverse shock in $z$ and the resulting decline in wage. Consider two scenarios. In one, the beginning-of-period capital is equal to the average capital stock over 640 periods, 193.970, and $z$ is equal to 
the average $z, 0.999$, implying a wage of 1.239 and a rate of return on capital of 0.094 per period. In the other, capital is again equal to its average value and $z$ is one standard deviation below average, at 0.967 , implying a wage of 1.199 and a rate of return on capital of 0.091. One measure of the young's potential loss in wages is the difference in wage between the two scenarios, 0.040. Since the difference in the rates of return on capital between the two scenarios is 0.003 and the average bond demand of the youngest age group is 12.782 , the youngest gain 0.038 in consumption units when the adverse shock hits. Hence the potential capital gain covers most of the loss.

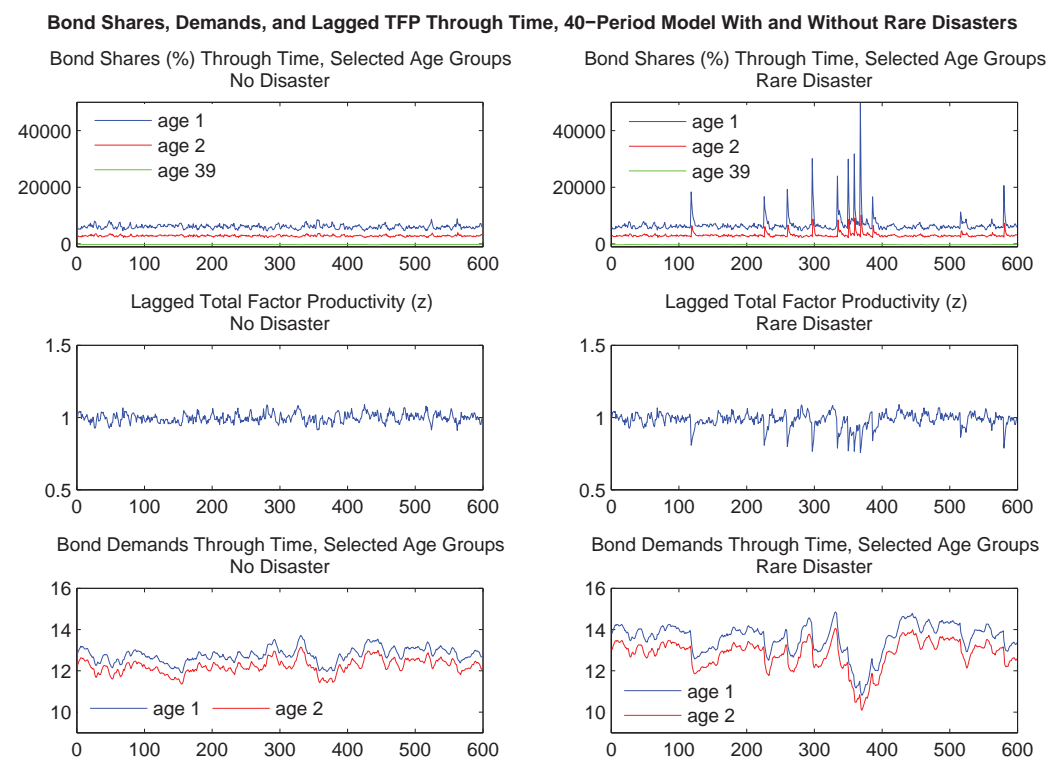

Figure 9: Bond shares and demands for selected age groups, and lagged total factor productivity level $(z)$, through time in the 40-period model with risk aversion of 2, with and without rare disasters. In the case of rare disasters, the probability of disaster in 1.7 percent per year, and contraction size during the disaster is 20 percent.

Bond demands fall off sharply with age even though assets rise rapidly during the accumulation phase. To understand further the behavior of bond demand, we plot, in Figure 9, bond shares and demands of selected age groups through time. Bond shares of the two youngest age groups are the most volatile, while those of the oldest age group exhibit very low volatility. This makes sense since when they are hit by adverse shocks, the young suffer heavy losses in the main source of their livelihood - their labor income. And, because of persistence in the process for $z$ 's, when a bad shock hits, the young insure themselves against further bad z's coming in the near future by buying bonds and shorting stocks. Since the bond shares they hold in the period after the bad shock reflect the decisions they made in 
the period the shock hit, we expect the correlation between the bond shares and lagged $z$ 's to be highly negative.

Indeed, the correlation between the bond shares and lagged $z$ 's is -97.8 percent in the model without rare disasters and -77.2 percent in the model with rare disaster for the youngest age group. In the case of rare disasters, the figure reveals that the largest spikes in bond shares coincide exactly with low lagged $z$ 's. However, the size of the bond share spikes of the youngest also depends on their beginning-of-period assets. If the largest bond share spikes are excluded from the calculation, the correlation between the bond shares and lagged $z$ 's in the model with rare disasters is lower -92.2 percent. The figure also reveals that bond demands of the young tend to drop after rare disasters hit even though bond shares rise, consistent with the fact that their investible assets are reduced. The old suffer less from drops in $z$ 's; although their capital gain is lower, their principal cannot be lost. This explains the lower variability in their bond shares.
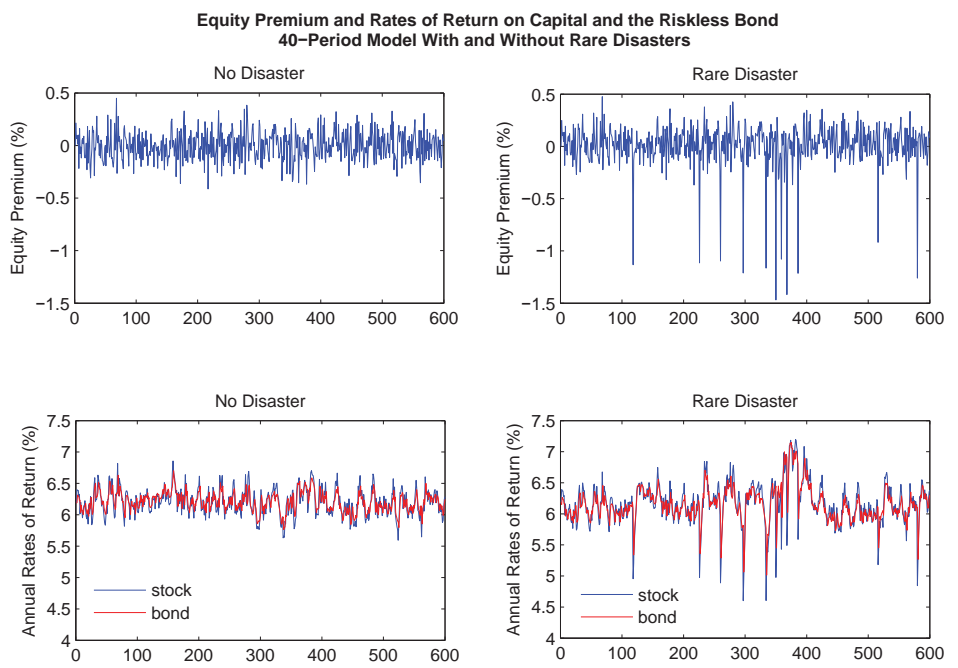

Figure 10: Equity premium and rates of return on capital and on the riskless bond in the 40-period model with and without rare disasters. In the case of rare disasters, the probability of disaster in 1.7 percent per year, and contraction size during the disaster is 20 percent. In all cases, risk aversion is 2 .

Figure 10 shows that the equity premium very small, regardless of the presence of rare disasters. Although in both models bond returns are less volatile than stock returns, on average bond and stock returns are virtually indistinguishable. In the model with rare disasters, the average annual rate of return on capital is 0.0617 with standard deviation of 0.0034. The average annual bond return is 0.0616 with standard deviation of 0.0027 . In the 
model without rare disasters the equity premium is even smaller. There, the average annual rate of return on both capital and bonds is $0.0620,{ }^{12}$ with standard deviations of 0.0021 for the stock and 0.0015 for the bond. Hence, rare disasters do not explain the high risk-free rate in our model.

What explains the model's small equity premium? One answer is simply that the risk arising from the productivity shock is not that large. But is this true? In the model without rare disasters and with bond, the mean wage is 1.239, and its standard deviation is only 0.048. But this ignores the persistence in the productivity shock process. Discounting at the average risk-free rate, a one standard deviation shock to the wage between the first and second year of life produces a present value loss in lifetime earnings of 0.236 or 1.74 percent of the average wage. ${ }^{13}$ This is non-trivial. But there are three other considerations. One is that shocks are i.i.d. and will likely average out over any worker's workspan. The second is that asset accumulation provides an effective means to self insure against productivity shocks especially since a negative productivity shock lowers today's capital formation, which raises tomorrow's future return to assets. Evidence of this self insurance is provided by the rapid decline in bond demand as workers age. The third is that there are ample number of elderly willing to underwrite the insurance young workers seek at an affordable price. I.e., they are willing to supply bonds at a low price (high return).

\subsubsection{0-Period Model and the Variable Policy: Consumption Co-movement Measures of Generational Risk}

To study the effect of the bond market on generational risk when incomes of the young and old are negatively correlated, we simulate a 20 -period model with variable policy. The countercyclical nature of the variable policy drives the correlation between the net wage and the rate of return on capital down to -94.55 percent. Such highly negatively correlated income risks leave scope for an improvement in risk sharing with the introduction of the bond.

In Table 5 we consider our three consumption co-movement measures of generational risk: pairwise correlations in percentage changes in consumption between different age groups, correlations of each agent's percentage change in consumption with the per capita consumption, and absolute percentage adjustments needed to achieve perfect risk sharing. The two

\footnotetext{
${ }^{12}$ The difference becomes visible only in the sixth decimal place.

${ }^{13}$ To compute the present value loss in lifetime earnings we again consider two scenarios. In one, the $z$ equals the average $z$ in the first year of life, is one standard deviation below average in the second year, and evolves according to (5) until retirement. In the other scenario, the $z$ starts at its average value in the first year of life, and thereafter evolves according to (5). The earnings loss each period is equal to the difference in wage implied by that period's $z$ in the two scenarios, keeping the capital at its average value in both cases.
} 


\begin{tabular}{|c|c|c|c|c|c|c|c|c|c|c|c|c|}
\hline & \multicolumn{3}{|c|}{$\begin{array}{l}\text { No Policy } \\
\text { No Bond }\end{array}$} & \multicolumn{3}{|c|}{$\begin{array}{l}\text { No Policy } \\
\text { With Bond }\end{array}$} & \multicolumn{3}{|c|}{$\begin{array}{l}\text { Variable Policy } \\
\text { No Bond }\end{array}$} & \multicolumn{3}{|c|}{$\begin{array}{l}\text { Variable Policy } \\
\text { With Bond }\end{array}$} \\
\hline & Min & Mean & Max & Min & Mean & Max & Min & Mean & Max & Min & Mean & Max \\
\hline$\rho\left(\% \Delta\right.$ in $C$ worker $_{i}, \% \Delta$ in C worker $\left._{j}\right)$ & 0.997 & 0.999 & 1.000 & 1.000 & 1.000 & 1.000 & -0.965 & 0.308 & 0.999 & 0.959 & 0.989 & 1.000 \\
\hline$\rho\left(\% \Delta\right.$ in $C$ retiree $_{i}, \% \Delta$ in $C$ retiree $\left.{ }_{j}\right)$ & 0.995 & 0.998 & 1.000 & 1.000 & 1.000 & 1.000 & 0.996 & 0.999 & 1.000 & 0.974 & 0.991 & 0.999 \\
\hline$\rho\left(\% \Delta\right.$ in $C$ agent $_{i}, \% \Delta{\left.\text { in } C \text { agent }_{j}\right)}$ & 0.963 & 0.988 & 1.000 & 1.000 & 1.000 & 1.000 & -0.974 & 0.037 & 1.000 & 0.839 & 0.958 & 1.000 \\
\hline 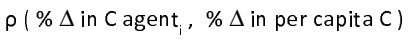 & 0.972 & 0.989 & 0.995 & 0.998 & 0.998 & 0.998 & -0.960 & -0.146 & 0.927 & 0.944 & 0.966 & 0.987 \\
\hline all agents: absolute $\%$ adjustment & 1.577 & 3.023 & 4.426 & 2.759 & 3.022 & 3.259 & 0.000 & 6.062 & 22.879 & 4.278 & 5.935 & 7.626 \\
\hline
\end{tabular}

Table 5: Measures of generational risk in the 20-period model with and without variable policy: summary statistics of pairwise correlations in percentage changes in consumption among different age groups, and absolute percentage adjustments needed to achieve full risk sharing. The first 50 observations (i.e. the capital stock transition period after the policies are introduced) have been dropped from all calculations.

left-hand-side panels present the results in models without policy and with and without bonds. As before in the 80- and 40-period models, they show that average consumption co-movement measures are very high and the absolute percentage adjustments, while larger, are still modest. Moreover, the improvement in risk sharing provided by the bond market is very limited.

The two right-hand-side panels present the results with variable policy, with and without bonds. As discussed in the 80-period model, pairwise correlations in percentage changes in consumption among some workers are highly negative since the policy turns good times into bad times for the workers, especially so for the youngest workers. However, the bond market allows them to effectively share risks among themselves and insure against positive $z$ 's. Indeed, the minimum across workers of their pairwise correlations in percentage changes in consumption increases from - 96.53 percent to 95.87 percent after the bond is introduced. The corresponding mean correlation increases from 30.83 percent to 98.94 percent after the bond is introduced.

Table 5 also shows that the bond reduces the volatility of absolute percentage adjustments. This is especially so in the case of variable policy, where the minimum absolute adjustment of 0.00 percent and the maximum absolute adjustment of 22.88 percent are both far from the mean adjustment of 6.06 percent. After the bond is introduced to the variable policy model, the spread of the minimum absolute adjustment (4.28 percent) and the maximum absolute adjustment (7.63 percent) around the mean absolute adjustment (5.93 percent) is much tighter. Figure 11, which plots the adjustments through time for the tenth age group, illustrates this striking reduction in volatility. Thus the bond market is important here, not to help agents hedge the riskiness of the economy, but rather to offset the riskiness 


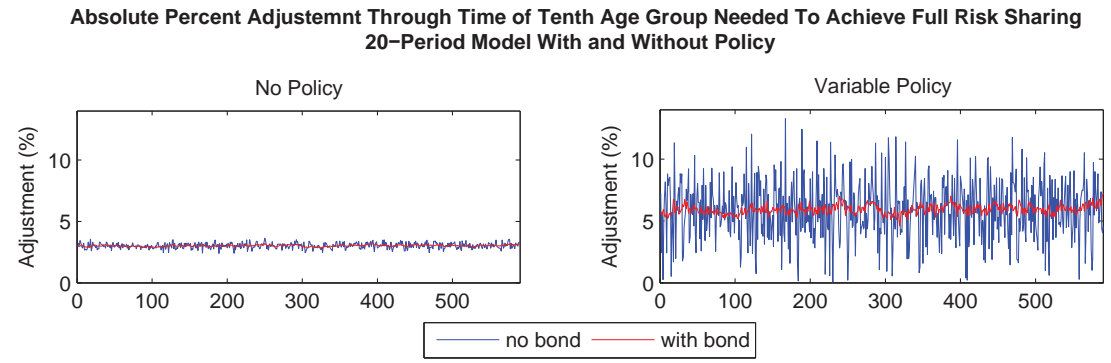

Figure 11: Absolute percentage adjustments needed to achieve perfect risk sharing for the 10th age group in the 20-period model with $\gamma=2$, with and without variable policy.

of the government policy.

\subsubsection{0-Period Model and Variable Policy: Bond Demands and the Equity Premium}

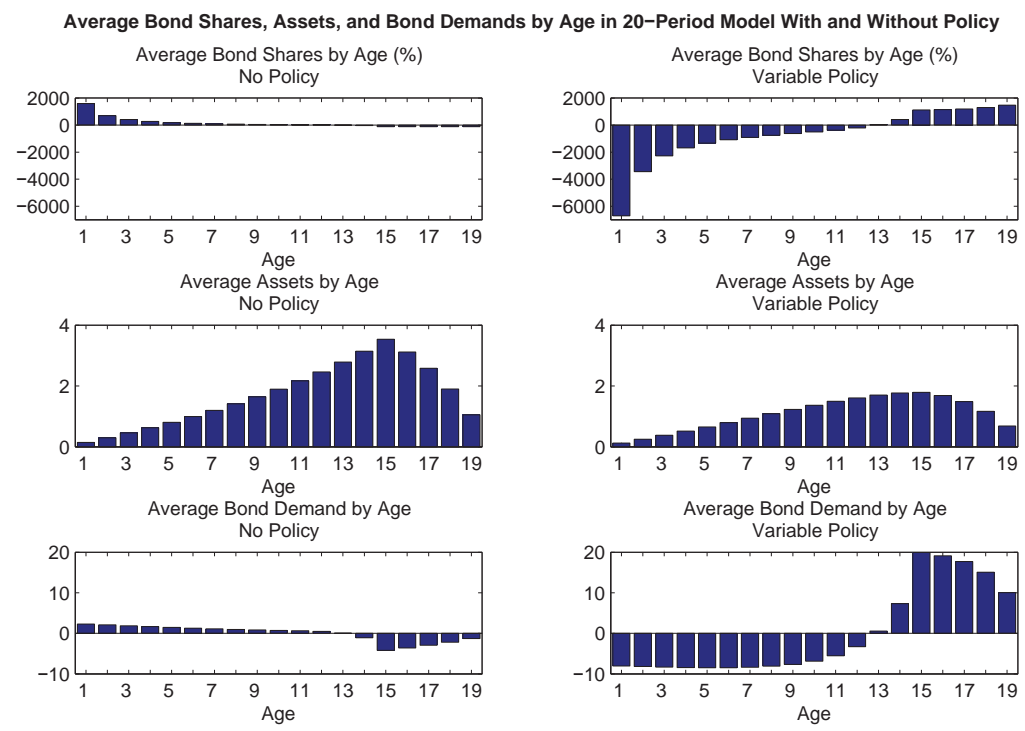

Figure 12: Average bond shares, assets, and bond demands by age in the 20-period model with $\gamma=2$, with and without variable policy.

Figure 12 plots average bond shares, assets, and bond demands by age. It shows that the pattern of bond demands flips when variable policy is introduced. As predicted, in the model with variable policy the young are insuring against the good times, which is when 
they get hurt by the government. To see this, note that they short bonds. They invest the proceeds of those short sales in stocks. Hence, when stocks do well, the resulting higher government taking is offset by increased capital gains.

On the other hand, the old need to insure themselves against the bad times. When adverse $z$ 's hit, the transfers they receive from the government are reduced. Moreover, in the model with policy, the asset holdings of the old are lower than in the model without policy, since in addition to their own savings they rely on the government. Hence, in bad times their interest income is lower in the model with policy. So they are the demanders of the bonds that the young supply.

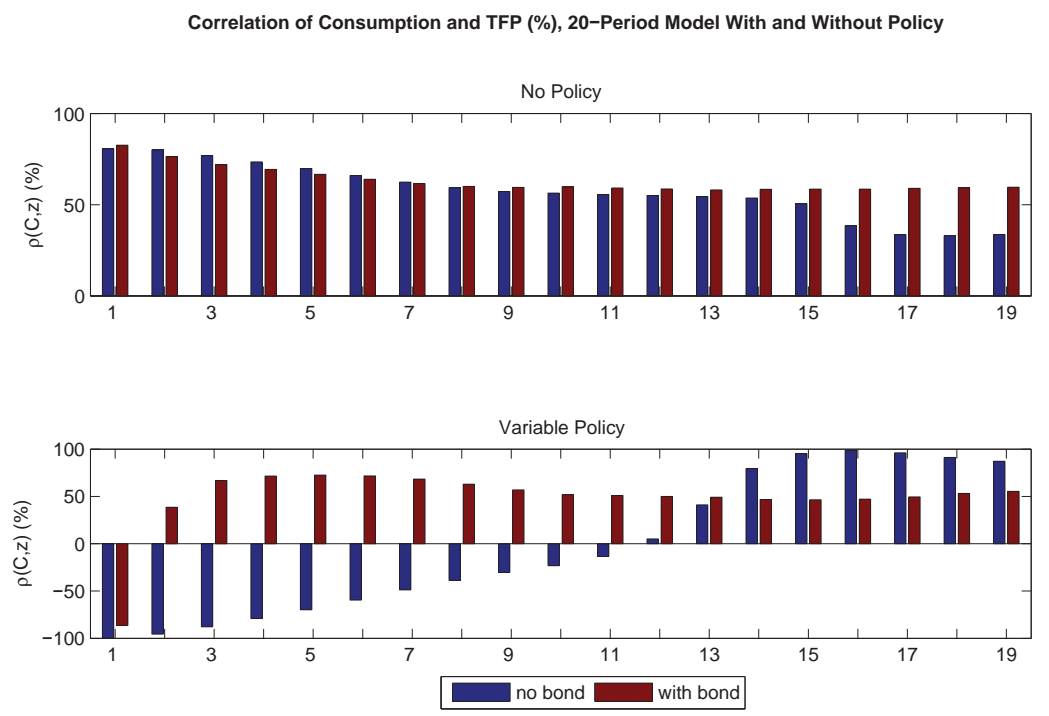

Figure 13: Correlation, in percent, between age-group-specific consumption and total factor productivity $(z)$ in the 20 -period model with $\gamma=2$, with and without variable policy.

Figure 13 plots the correlations, in percent, between the age-group-specific consumption and the shock $z$. It shows that, unlike in the model without policy, in the model with policy, bond positions of the young dramatically alter their correlations. ${ }^{14}$ Hence, the bond market provides a practical generational risk sharing mechanism in the model with variable policy.

The effectiveness of bonds in insuring the young in the model with variable policy is also evidenced by the fact that adding the bond market increases the volatility (the standard deviation) of the capital stock from 0.693 to 1.018. This makes sense, since the bond makes the good times even better and the bad times even worse for the young, and hence increases

\footnotetext{
${ }^{14}$ The very first age group enters each period without any assets or bond positions, hence the bond does not flip the sign of the correlation of their consumption with the shock $z$ with respect to the model without bond.
} 
the upside and lowers the downside of how much they can save. In the model without policy the effect of the bond market on the volatility of the capital stock is much less pronouncedit decreases from 1.399 to 1.264 after the bond is introduced. This is consistent with our previous evidence of it playing a very limited role in terms of risk sharing when income risks are positively correlated.

Despite all the risk sharing the bond accommodates in the model with variable policy, the equity premium, computed as the average, across 640 periods, of the difference between the rates of return on the stock and the bond, remains small. In fact, the equity premium of $9.64 \times 10^{-6}$ in the model without policy is virtually indistinguishable from that of $2.41 * 10^{-5}$ in the model with variable policy. As before, the reason is that the average risk-free rate is almost as high as the average rate of return on capital: in the model with policy the average rates of return are 0.0818 for the stock and 0.0817 for the bond, while in the model without policy they are 0.0620 for both the stock and the bond. Hence, uncorrelated income risks cannot explain the equity premium puzzle in our model.

\subsubsection{0-Period Model with High Risk Aversion and Rare Disasters: Consump- tion Co-movement Measures of Generational Risk}

To further investigate the equity premium puzzle, we simulate two more 20-period models: one with very high risk aversion $(\gamma=15)$ and another with a combination of high risk aversion $(\gamma=6)$ and rare disasters.

\begin{tabular}{|c|c|c|c|c|c|c|c|c|c|c|c|c|}
\hline & \multicolumn{3}{|c|}{$\begin{array}{c}\gamma=15 \\
\text { No Disasters } \\
\text { No Bond }\end{array}$} & \multicolumn{3}{|c|}{$\begin{array}{c}Y=15 \\
\text { No Disasters } \\
\text { With Bond }\end{array}$} & \multicolumn{3}{|c|}{$\begin{array}{c}\quad \gamma=6 \\
\text { Rare Disasters } \\
\text { No Bond }\end{array}$} & \multicolumn{3}{|c|}{$\begin{array}{c}\quad \gamma=6 \\
\text { Rare Disasters } \\
\text { With Bond }\end{array}$} \\
\hline & Min & Mean & Max & Min & Mean & Max & Min & Mean & Max & Min & Mean & Max \\
\hline$\rho\left(\% \Delta\right.$ in $\mathrm{C}$ worker $_{i}, \% \Delta$ in $\mathrm{C}$ worker $\left._{j}\right)$ & 0.98 & 1.00 & 1.00 & 1.00 & 1.00 & 1.00 & 0.98 & 0.99 & 1.00 & 0.99 & 1.00 & 1.00 \\
\hline$\rho\left(\% \Delta\right.$ in $\mathrm{C}_{\text {retiree }}, \% \Delta$ in $\mathrm{C}_{\mathrm{i}}$ retiree $\left.{ }_{\mathrm{j}}\right)$ & 0.80 & 0.93 & 1.00 & 0.98 & 0.99 & 1.00 & 0.81 & 0.93 & 1.00 & 0.98 & 0.99 & 1.00 \\
\hline$\rho\left(\% \Delta\right.$ in $\mathrm{C}$ agent $_{\mathrm{i}}, \% \Delta$ in $\mathrm{C}$ agent $\left._{\mathrm{j}}\right)$ & 0.80 & 0.97 & 1.00 & 0.98 & 1.00 & 1.00 & 0.81 & 0.96 & 1.00 & 0.98 & 1.00 & 1.00 \\
\hline 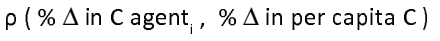 & 0.83 & 0.98 & 0.99 & 0.98 & 1.00 & 1.00 & 0.85 & 0.97 & 0.99 & 0.99 & 0.99 & 1.00 \\
\hline all agents: absolute \% adjustment & 0.00 & 1.61 & 3.86 & 0.96 & 1.63 & 2.75 & 0.01 & 2.15 & 6.48 & 0.13 & 2.16 & 4.22 \\
\hline
\end{tabular}

Table 6: Measures of generational risk in the 20-period model with very high risk aversion $(\gamma=15)$ and no rare disasters, and with a combination of high risk aversion $(\gamma=6)$ and rare disasters: summary statistics of pairwise correlations in percentage changes in consumption among different age groups, and absolute percentage adjustments needed to achieve full risk sharing. In the case of rare disaster, the probability of disaster in 1.7 percent per year, and contraction size during the disaster is 15 percent. 


\begin{tabular}{|c|c|c|c|c|c|c|}
\hline \multicolumn{4}{|c|}{ Model } & \multicolumn{3}{|c|}{ Correlation (\%) } \\
\hline $\boldsymbol{Y}$ & $\begin{array}{l}\text { Rare } \\
\text { Disaster }\end{array}$ & Policy & Bond & $\rho($ net $w, r)$ & $\rho($ gross $w, z)$ & $t \mathbf{w}, \mathbf{z})$ \\
\hline 2 & No & None & No & 37.20 & 93.06 & 93.06 \\
\hline 2 & No & None & Yes & 45.36 & 94.22 & 94.22 \\
\hline 2 & No & Variable & No & -94.55 & 99.52 & -99.52 \\
\hline 2 & No & Variable & Yes & -47.88 & 94.81 & -94.81 \\
\hline 15 & No & None & No & -53.54 & 68.06 & 68.06 \\
\hline 15 & No & None & Yes & -42.08 & 73.83 & 73.83 \\
\hline 6 & Yes & None & No & -31.52 & 82.22 & 82.22 \\
\hline 6 & Yes & None & Yes & -18.60 & 85.50 & 85.50 \\
\hline
\end{tabular}

Table 7: Correlations of wage (where applicable, both gross and net of government taking) with the rate of return on capital and the $z$ 's in various 20-period models.

Table 6 displays our consumption co-movement measures of generational risk for each model, with and without bond. It shows that generational risk is very small to start with, and that the bond has very limited effect in mitigating it. This is despite the fact that the correlation between the wage and the interest rate is negative, as reported in Table 7. However, unlike in the variable policy model, in these two models the correlation between the wage and the $z$ 's is highly positive. It is 68.06 percent and 73.83 percent in the very high risk aversion model without and with bonds, respectively, and 82.22 percent and 85.50 percent in the high risk aversion and rare disasters model without and with bonds, respectively. At the same time, the correlation of the rate of return on capital with the $z$ 's is also positive: 25.10 percent, 29.93 percent, 27.73 percent, and 34.83 percent in the very high risk aversion model without and with bond, and in the high risk aversion with rare disasters model without and with bond, respectively. Hence, both the young and the old suffer in bad times, and risk sharing opportunities are limited.

\subsubsection{0-Period Model with High Risk Aversion and Rare Disasters: Asset Demands and the Equity Premium}

However, the old suffer less than the young when bad shocks hit, as evidenced by the lower correlations of rate of return on capital with the $z$ 's compared to the corresponding correlations of wages with the z's. Hence, they are the demanders of bonds in these two models, while the old are the suppliers, as Figure 14 shows.

The equity premium remains very small, at $5.3080 \times 10^{-4}$ in the model with very high risk aversion and at $3.9004 \times 10^{-4}$ in the model with high risk aversion and rare disasters. Again, this is due to the high risk free rate: the average rates of return are 0.1239 for the bond and 0.1245 for the stock in the $\gamma=15$ model, and 0.0845 for the bond and 0.0849 for 


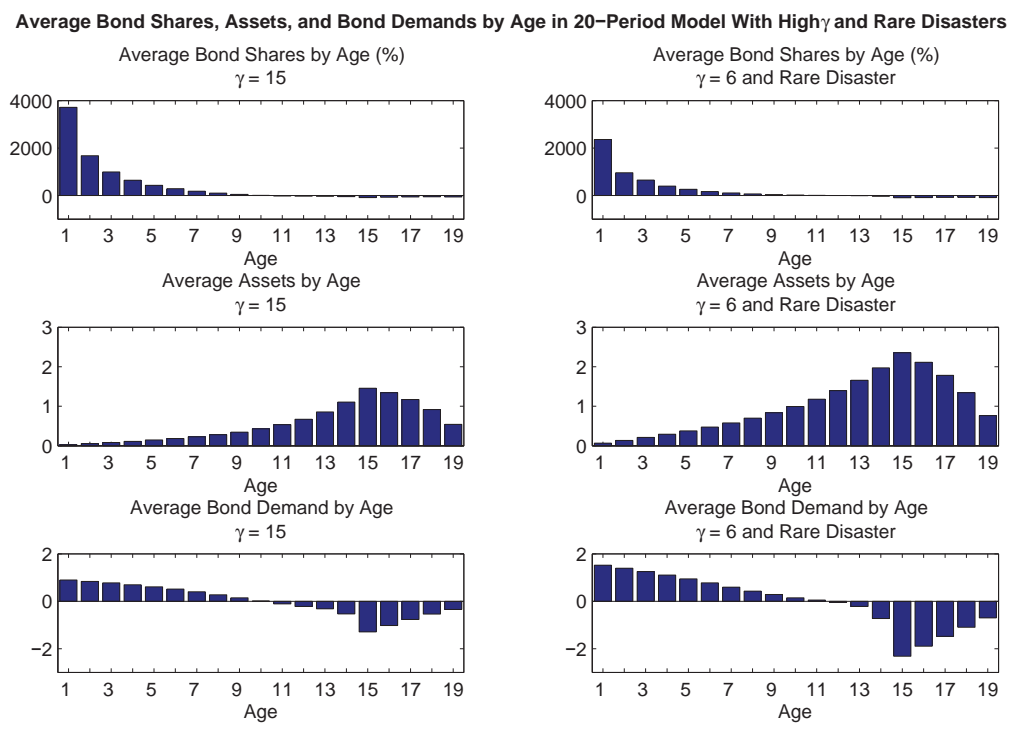

Figure 14: Average bond shares, assets, and bond demands by age in the 20-period model with very high risk aversion $(\gamma=15)$ and no rare disasters, and with a combination of high risk aversion $(\gamma=6)$ and rare disasters. In the case of rare disasters, the probability of disaster in 1.7 percent per year, and contraction size during the disaster is 15 percent.

the stock in the $\gamma=6$ with rare disasters model. Hence, high risk aversion and rare disasters do not explain the equity premium puzzle in our model.

The finding of small equity premia in a wide range of papers does not imply a common explanation as the models used differ substantially with respect to the nature of technology, preferences of agents, the horizons of agents, the number of periods, the types of shocks, the presence of borrowing constraints, and the age-specific covariance of equity returns and wages. $^{15}$

In our model, equity premia appear to be small for three reasons. First, the annual productivity shocks hitting the economy, while realistically calibrated, are relatively modest even when rare disasters are incorporated. Hence, there is relatively little intrinsic generational risk. Second, in models without variable policy, intrinsic generational risk hits both the young and the old in similar ways. Rather than sharing risks among themselves, agents self insure by saving and accumulating significant assets over the life cycle, i.e. they pool risk over time. While the return on these assets is risky, the principle itself cannot be lost. Over time, as workers age, this diminishes the demand for bonds as a way of securing sure resources. This explains why the very young are most interested in buying bonds and the

\footnotetext{
${ }^{15}$ Constantinides, Donaldson, and Mehra (2002), for example, assume the young have safe wages and would be natural purchasers of stock and sellers of bonds were it not for borrowing constraints.
} 
very old are more interested in selling them. And third, artificially inducing risk between the young and the old via government policy elicits more net supply as well as net demand for bonds, by the young and the old respectively, leaving the risk premium essentially unchanged.

\section{Sensitivity Analysis}

To assess the robustness of our finding of small generational risk, we also simulated models with stochastic depreciation and a random walk specification of the technology process.

\subsection{Stochastic Depreciation}

Although we view stochastic depreciation as a rather ad-hoc way of breaking the positive correlation between stock returns and wages, we include it in the 20-period model to see its impact on generational risk. Specifically, we follow Ambler and Paquet (1994) and specify the depreciation rate as a normal random variable with quarterly mean, standard deviation, and covariance with the technology shock of $0.021,0.0052$, and $-2.07 \times 10^{-6}$. This produces correlations of -0.097 between the wage and the rate of return on capital, 0.822 between the wage and the $z$ 's, and 0.078 between the rate of return on capital and the $z$ 's. ${ }^{16}$ The corresponding correlations in the baseline 20-period model without depreciation are 0.372 , 0.931 , and 0.686 .

Nevertheless, Table 8 reveals only a small increase in generational risk compared to the baseline model without stochastic depreciation according to the consumption co-movement measures. For example, the average across all agents of their correlations in percentage changes in consumption is 0.883 which is only slightly smaller than the corresponding 0.988 value from the baseline model without depreciation. And the average percentage adjustment of 2.009 in the model with stochastic depreciation is actually smaller than the 3.023 value in the baseline model, but the spread of the adjustments is larger in the model with depreciation.

There are two reasons stochastic depreciation is less effective in generating generational risk than one might think. First, an $X$ percent depreciation-induced reduction in the stock of capital in period $t$ will be mitigated, from the perspective of capital owners, by increases in the marginal productivity of capital in period $t+1$ and thereafter. Second, the reduction in capital hurts workers via a reduction in the marginal productivity of labor, i.e., in wages

\footnotetext{
${ }^{16}$ Since we start the simulation from the non-stochastic steady state of the 20-period model without depreciation, the first 50 periods of the simulation represent the transition period during which the capital stock moves to its new level. Hence, we exclude the first 50 periods from the calculations of the correlations and the generational risk measures.
} 
in this period and thereafter. Hence, there is natural risk sharing arising via these general equilibrium effects.

\subsection{Random Walk Technology}

The technology process we considered so far is $\mathrm{AR}(1)$, hence mean reverting. To attempt to produce more pronounced generational risks and see what implications they might have across generations, we simulate a 20 -period model with a random walk specification of the technology process, viz.,

$$
\ln \left(z_{t+1}\right)=\ln \left(z_{t}\right)+\epsilon_{t+1}
$$

where $\epsilon_{t+1}$ is a normal random variable calibrated as in (5).

Table 8 again shows only a small increase in generational risk compared to the baseline model: consumption correlations are now 0.847 , on average, and the average percentage adjustment is 3.119 .

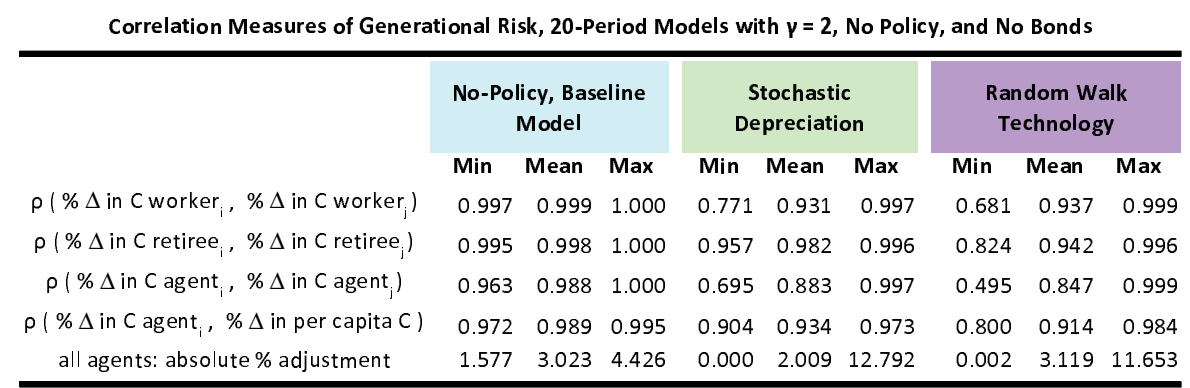

Table 8: Measures of generational risk in 20-period models with stochastic depreciation (and $\mathrm{AR}(1)$ technology) and random walk technology (and no depreciation): summary statistics of pairwise correlations in percentage changes in consumption among different age groups, and absolute percentage adjustments needed to achieve full risk sharing. The first 50 observations (i.e. the capital stock transition period after stochastic depreciation or policy are introduced) have been dropped from all calculations. The baseline model, included for comparison, is with AR(1) technology and without depreciation. All models are without policy, without bonds, and with $\gamma$ of 2 . 


\subsection{The Small Gains from Fully Sharing Risk Among Living Gen- erations}

Our consumption co-movement measures of generational risk are less than fully satisfying because they do not clarify the expected utility gains from actually implementing such risk sharing. Figures 15 and 16 do this. They present the compensating differentials for each cohort of newborns in the absence of such risk sharing arrangements needed to achieve the same level of expected utility as in the presence of such arrangements. The compensating differentials are, as above, the common factor by which one needs to multiply consumption levels along all paths of the economy absent the envisaged risk sharing to produce the same expected utility as would arise with the envisaged risk sharing.

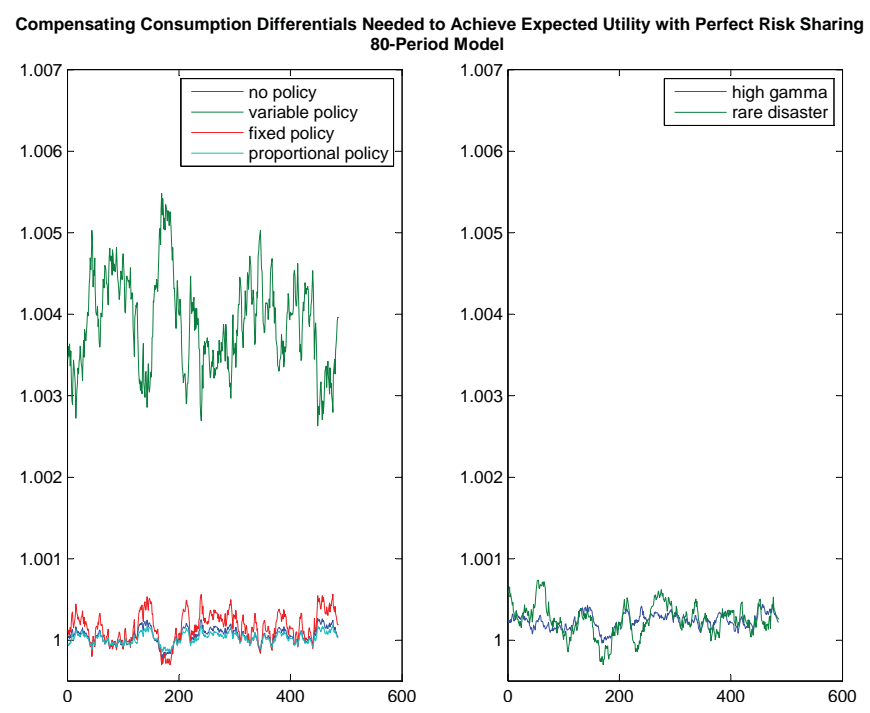

Figure 15: Compensating consumption differentials of newborns through time needed to equate their expected lifetime utility in the original simulation to that in the world with perfect risk sharing in the 80-period models. In models labeled "no policy", "variable policy", "fixed policy", and "proportional policy" the risk aversion is 2 and there are no rare disasters; in the model labeled "high gamma" the risk aversion is 5 and there are no rare disasters; in the model labeled "rare disaster", the risk aversion in 2, the probability of disaster in 3 percent per year, and contraction size during the disaster is 20 percent. The first 75 observations (i.e. the capital stock transition period after policies are introduced) have been dropped from all calculations. All models are without bonds.

To calculate expected utility with full risk sharing among the living we imagine the following agreement made by each contemporaneous generation age 1 to 79 at each point in time $t$ that governs who will consume what at time $t+1$. Each generation takes the 


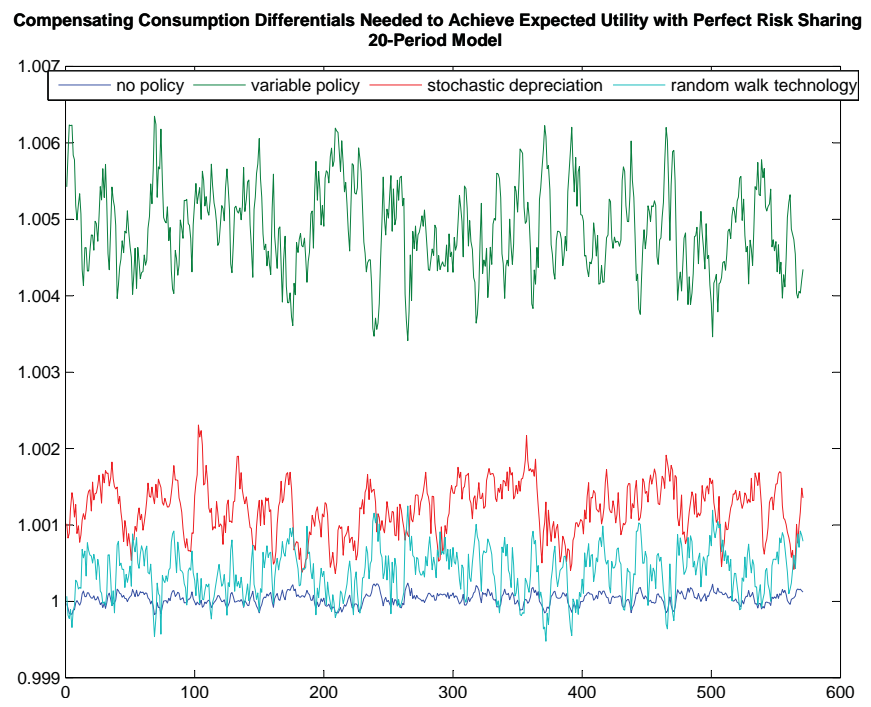

Figure 16: Compensating consumption differentials of newborns through time needed to equate their expected lifetime utility in the original simulation to that in the world with perfect risk sharing in the 20-period models. The model labeled "no policy" is our baseline model without policy, without depreciation, and with $\mathrm{AR}(1)$ technology. The "stochastic depreciation" model is without policy and with $\mathrm{AR}(1)$ technology, and "random walk technology" model is without policy and without stochastic depreciation. The "variable policy" model is without stochastic depreciation and with $\mathrm{AR}(1)$ technology. The first 50 observations (i.e. the capital stock transition period after stochastic depreciation or policy are introduced) have been dropped from all calculations. All models are without bonds and with $\gamma$ of 2 . 
consumption it would do in the absence of the agreement as its threat point and agrees to experience the same growth rate in consumption between $t$ and $t+1$ as everyone else, with aggregate consumption growth calculated as the percentage change in the sum of threat point consumptions of those 1 to 79 at time $t$ and the sum of threat point consumptions of those age 2 to 80 at time $t+1$.

Note that by always consuming, in the aggregate, the total threat point level of consumption, the economy's capital stock along its risk-sharing path always remains the same as without the risk-sharing. In addition, each generation's assets in each period will equal what it would otherwise have held in assets without the risk sharing since if the agreement calls for them to consume less than they would otherwise have done, they give up some of their current consumption rather than use up their remaining assets. And if the agreement calls for them to consume more than they would otherwise have consumed, they receive the additional consumption from their contemporaries, not via a dissipation of their own asset holdings.

As Figure 15 shows, the expected utility gains from implementing full risk sharing among those alive at any point in time are less than one tenth of one percent in the 80-period model with no policy, fixed policy, and proportional policy as well as with no policy and high risk aversion or no policy and rare disasters. ${ }^{17}$ In the case of variable policy, the gain to risk sharing does, for a few generations, exceed one half of one percent.

Figure 16 repeats Figure 15, but for 20-period models with no policy, variable policy, stochastic depreciation, and productivity shocks that follow a random walk. The results are very similar to those in the prior figure.

\section{Conclusion}

The theoretical literature on generational risk assumes this risk is meaningful and can be shared by the government. To assess the validity of these assumptions this paper develops, calibrates, and simulates 80-period, 40-period, and 20-period OLG models with aggregate productivity shocks.

We find that generational risk is overrated and illustrate how government take-as-you-go policy can manufacture, rather than mitigate generational risk. We show that the main determinant of the economy's future position is not the shocks it experiences, but rather the manner and extent to which the government redistributes resources across generations. We also demonstrate that bond markets can play an important role in sharing risk across

\footnotetext{
${ }^{17}$ The values in the figure that are less than 1 reflect, we believe, approximation errors.
} 
generations, including the generational risk arising from government policy. Finally, we confirm in an OLG framework that equity premium in simple neoclassical models is far smaller than that observed.

Previous solution methods could not handle large scale models such as ours due to the well known curse of dimensionality. We overcome the curse by restricting the model's solution to its ergodic set based on the suggestion of Marcet (1988) and the associated solution algorithm developed by Judd, Maliar, and Maliar (2009, 2011). We extend the latter to include an inner loop to clear the bond market. This paper demonstrates the practicability of constructing large-scale OLG models with aggregate shocks in which generational policy matters as appears so evident in real economies. 


\section{References}

Abel, A. and L. J. Kotlikoff, 1988, "Does the Consumption of Different Age Groups Move Together? A New Nonparametric Test of Intergenerational Altruism", NBER Working Papers 2490, National Bureau of Economic Research.

Ambler, S. and A. Paquet, 1994, "Stochastic Depreciation and the Business Cycle", International Economic Review 35, 101-116.

Ball, L. and N. G. Mankiw, 2007, "Intergenerational Risk Sharing in the Spirit of Arrow, Debreu, and Rawls, with Applications to Social Security Design", Journal of Political Economy 115, 523-547.

Barro, R. J., 2006, "Rare Disasters and Asset Markets in the Twentieth Century", The Quarterly Journal of Economics 121, 823-866.

Bodie, Z., R. C. Merton, and W. F. Samuelson, 1992, "Labor Supply Flexibility and Portfolio Choice in a Life Cycle Model", Journal of Economic Dynamics and Control 16, 427-449.

Bohn, H., 1998, "Risk Sharing in a Stochastic Overlapping Generations Economy", University of california at santa barbara, economics working paper series, Department of Economics, UC Santa Barbara.

Constantinides, G. M., J. B. Donaldson, and R. Mehra, 2002, "Junior Can't Borrow: A New Perspective On the Equity Premium Puzzle", The Quarterly Journal of Economics 117, 269-296.

Davis, S. J. and P. Willen, 2000, "Using Financial Assets to Hedge Labor Income Risks: Estimating the Benefits", Working Paper.

Furlanetto, F. and M. Seneca, 2011, "New Perspectives on Depreciation Shocks as a Source of Business Cycle Fluctuations", Technical report, Norges Bank.

Gourinchas, P.-O., 2000, "Precautionary Savings, LifeCycle and Macroeconomics", Econometric Society World Congress 2000 Contributed Papers 0793, Econometric Society.

Green, J. and L. J. Kotikoff, 2008, "On the General Relativity of Fiscal Language", in A. J. Auerbach and D. N. Shaviro, editors, "Institutional Foundations of Public Finance", Cambridge: Harvard University Press. 
Judd, K., L. Maliar, and S. Maliar, 2009, "Numerically Stable Stochastic Simulation Approaches for Solving Dynamic Economic Models", NBER Working Papers 15296, National Bureau of Economic Research.

Judd, K., L. Maliar, and S. Maliar, 2011, "Numerically Stable Stochastic Simulation Approaches for Solving Dynamic Economic Models", Quantitative Economics 2, 173-210.

Krueger, D. and F. Kubler, 2004, "Computing Equilibrium in OLG Models with Stochastic Production", Journal of Economic Dynamics and Control 28, 1411-1436.

Krueger, D. and F. Kubler, 2006, "Pareto-Improving Social Security Reform when Financial Markets are Incomplete!?", American Economic Review 96, 737-755.

Krusell, P. and A. A. Smith, 1997, "Income And Wealth Heterogeneity, Portfolio Choice, And Equilibrium Asset Returns", Macroeconomic Dynamics 1, 387-422.

Krusell, P. and A. A. Smith, 1998, "Income and Wealth Heterogeneity in the Macroeconomy", Journal of Political Economy 106, 867-896.

Krusell, P. and A. A. Smith, 1999, "On the Welfare Effects of Eliminating Business Cycles", Review of Economic Dynamics 2, 245-272.

Lucas, R. E., 1987, Models of Business Cycles, Oxford: Basil Blackwell.

Malin, B. A., D. Krueger, and F. Kubler, 2011, "Solving the Multi-Country Real Business Cycle Model Using a Smolyak-Collocation Method", Journal of Economic Dynamics and Control 35, 229-239.

Marcet, A., 1988, "Solution of Nonlinear Models by Parameterizing Expectations", Technical report, Carnegie Mellon University.

Merton, R. C., 1983, "On the Role of Social Security as a Means for Efficient Risk-Bearing in an Economy Where Human Capital Is Not Tradeable", in Z. Bodie and J. Shoven, editors, "Financial Aspects of the United States Pension System", Chicago: University of Chicago Press.

Rangel, A. and R. Zeckhauser, 2001, "Can Market and Voting Institutions Generate Optimal Intergenerational Risk Sharing?", in "Risk Aspects of Investment-Based Social Security Reform", NBER Chapters, National Bureau of Economic Research, 113-152.

Rawls, J., 1971, A Theory of Justice, Cambridge, MA: Belknap Press of Harvard University Press. 
Rietz, T. A., 1988, "The Equity Risk Premium: A Solution", Journal of Monetary Economics $22,117-131$.

Rios-Rull, J.-V., 1994, "On the Quantitative Importance of Market Completeness", Journal of Monetary Economics 34, 463-496.

Rios-Rull, J.-V., 1996, "Life-Cycle Economies and Aggregate Fluctuations", Review of Economic Studies 63, 465-489.

Shiller, R., 1999, "Social Security and Intergenerational, Intragenerational, and International Risk Sharing", Carnegie-Rochester Conference Series on Public Policy 50, 165-204.

Smetters, K. A., 2003, "Trading with the Unborn: A New Perspective on Capital Income Taxation", NBER Working Papers 9412, National Bureau of Economic Research.

Storesletten, K., C. Telmer, and A. Yaron, 2007, "Asset Pricing with Idiosyncratic Risk and Overlapping Generations", Review of Economic Dynamics 10, 519-548.

Weitzman, M. L., 2007, "Subjective Expectations and Asset-Return Puzzles", American Economic Review 97, 1102-1130. 